\title{
Studies of Structural and Electrical Characteristics of Multi-substituted Bi0.5Na0.5TiO3 Ferroelectric Ceramics
}

\section{B. B. Arya ( $\sim$ bbarya96@gmail.com )}

Siksha 'O' Anusandhan (Deemed to be university), Bhubaneswar https://orcid.org/0000-0002-58693474

\section{R N P Choudhary}

Siksha O Anusandhan University Institute of Technical Education and Research Department of Physics

\section{Research Article}

Keywords: X-ray diffraction, Dielectrics, Impedance, Ferroelectric, Leakage current

Posted Date: March 15th, 2021

DOI: https://doi.org/10.21203/rs.3.rs-292550/v1

License: (c) (i) This work is licensed under a Creative Commons Attribution 4.0 International License.

Read Full License

Version of Record: A version of this preprint was published at Journal of Materials Science: Materials in Electronics on April 10th, 2021. See the published version at https://doi.org/10.1007/s10854-021-057437. 


\title{
Studies of Structural and Electrical Characteristics of Multi-substituted $\mathrm{Bi}_{0.5} \mathrm{Na}_{0.5} \mathrm{TiO}_{3}$ Ferroelectric Ceramics
}

\author{
B.B. Arya ${ }^{*}, \mathrm{R} N \mathrm{P}$ Choudhary \\ Multifunctional Research laboratory, Department of physics, \\ Siksha 'O' Anusandhan, (Deemed To Be University), Bhubaneswar, Odisha, India
}

\begin{abstract}
In this communication, preliminary structural and detailed electrical characteristics of the $\mathrm{CaSnO}_{3} / \mathrm{CaSeO}_{3}$ modified $\mathrm{Bi}_{0.5} \mathrm{Na}_{0.5} \mathrm{TiO}_{3}$ ceramics of a general chemical composition (1-2x) $\left[\mathrm{Bi}_{0.5} \mathrm{Na}_{0.5} \mathrm{TiO}_{3}\right]+\mathrm{x}\left(\mathrm{CaSnO}_{3}\right)+\mathrm{x}\left(\mathrm{CaSeO}_{3}\right)$ with $\mathrm{x}=0,0.05,0.10,0.15$, prepared by hightemperature solid-state reaction method with calcination and sintering temperature $925{ }^{\circ} \mathrm{C}$ and $950^{\circ} \mathrm{C}$ respectively for $5 \mathrm{~h}$, have been reported. Structural and electrical characteristics of the parent compound have significantly been tailored by the addition of the equal percentage of $\mathrm{CaSnO}_{3}, \mathrm{CaSeO}_{3}$ over a wide range of temperature $\left(25^{\circ} \mathrm{C}-400{ }^{\circ} \mathrm{C}\right)$ as well as frequency $(1 \mathrm{kHz}-$ $1 \mathrm{MHz}$ ). Analysis of room temperature X-ray diffraction (XRD) data confirmed the development of single-phase compound (with rhombohedral symmetry) with very small amount of impurity phase with higher concentrations (x). In the dielectric spectroscopy, two dielectric peaks are observed at around temperatures $210{ }^{\circ} \mathrm{C}$ and $320{ }^{\circ} \mathrm{C}$ indicating multiple phase transitions of different types including the ferroelectric to para-electric through anti-ferroelectric. Impedance analysis of data exhibits both negative/positive temperature coefficient of temperature (i.e., semiconductor behavior) of the materials. The Nyquist plots determine the grain and grain boundary effect in capacitive and resistive properties of the materials, and also the non-Debye type of relaxation. The room temperature hysteresis loop confirms the existence of ferroelectricity in the materials. The leakage current characteristics also determine the Ohmic behavior of the materials.
\end{abstract}

*B.B. Arya

Email: bbarya96@gmail.com

Key Words: X-ray diffraction, Dielectrics, Impedance, Ferroelectric, Leakage current 


\section{Introduction}

In the last few decades, some lead-based ceramics with perovskite $\left(\mathrm{ABO}_{3}\right)$ type of structure including $\mathrm{Pb}(\mathrm{Zr}, \mathrm{Ti}) \mathrm{O}_{3}$ (PZT) have been fabricated and studied for industrial applications, such as ultrasonic transducers, sensors, actuators, microelectronic devices as well as energy harvesters because of their outstanding electrical properties [1-3]. However, due to the presence of a large percentage (about 60\%) of lead in PZT (i.e., the high toxicity of lead oxide), the above leadbased electronic devices have produced serious environmental pollution which is very harmful to the human body during their fabrications and usage procedures [4-6]. Hence, the development of lead-free ferroelectric ceramics is required urgently and has always become a popular topic in this research field also draws the attention of researchers [7, 8]. Among various lead-free materials, bismuth sodium titanate $\left(\mathrm{Bi}_{0.5} \mathrm{Na}_{0.5}\right) \mathrm{TiO}_{3}$ (commonly known as BNT) is considered as one of the most favorable ferroelectric ceramics having perovskite-structure with rhombohedral (R3c) symmetry at room temperature [9, 10]. Since the first discovery of BNT4 in1960s by Smolenskii et al. [11]. It has extensively been studied and given lots of attention because of its large value of remnant polarization $\left(\mathrm{P}_{\mathrm{r}}\right)$ of $38 \mu \mathrm{C} \mathrm{cm}^{-1}$ and high Curie temperature $\left(\mathrm{T}_{\mathrm{c}}\right)$ of $320^{\circ} \mathrm{C}$ $[12,13]$. Although BNT ceramic has many good characteristics, it has a few drawbacks also including poor dielectric performances, difficulty to pole sufficiently because of the high value of coercive field $\left(E_{c}\right)$ of $73 \mathrm{kV} / \mathrm{cm}$, the high value of electric conductivity, and volatization of $\mathrm{Bi}$ ion at the time of sintering at high temperature. To avoid/solve these problems to enhance the material properties, suitable substitution at different sites or addition of some perovskite materials in the parent compound has been attempted $[14,15]$. In the present work calcium stannate $\left(\mathrm{CaSnO}_{3}\right)$ and calcium selenate $\left(\mathrm{CaSeO}_{3}\right)$ with equal ratios (i.e., $\mathrm{x}=5 \%, 10 \%$, and $\left.15 \%\right)$ have been added to the pure BNT compound, so that in the A site along with bismuth (Bi) and sodium $(\mathrm{Na})$ a new calcium ion $(\mathrm{Ca})$ is created, In the same manner for B site $\mathrm{Ti}(\mathrm{Sn})$ and selenium (Se) atoms are added together with titanium (Ti), hence the title multi-substituted $\mathrm{Bi}_{0.5} \mathrm{Na}_{0.5} \mathrm{TiO}_{3}$ ceramics is justified.

Now-a-days sonochemical pathway is widely used for the creation of nanoscale compounds of different shapes [16]. Ultrasound is applied as a rapid process for different tasks like dispersion of materials as well as architectural control of nanostructures. Cavitation formed with the support of ultrasound waves may bring favorable and specific structures with high uniformity at the 
nanoscale. Previously it is reported that acoustic cavitation (including phases of creation, growth, and implosive collapse of bubbles in the solution) requires the efficiency of sonication $[16,17]$. Sonication is the work, where sound energy is applied for particle agitation in the sample for different purposes like multiple compound extractions from plants, microalgae, and seaweeds. Ultrasonic frequency $(>20 \mathrm{kHz})$ is generally used in this process, hence known as ultrasonication. Generally, it is demonstrated that the attributes and functionality of the nano compounds can be affected by key variables consisting of dimensionality, shape, purity, structure, composition, and grain size. Due to this reason, their fabrication with optimizing the mentioned variables has gained a great deal of attention, and has become a remarkable topic for researcher [18-20]. Moreover, it is also found that the change in these effectual factors causes variation in the characteristics of the nano compounds [21]. The nano compounds are generally prepared by both physical and chemical processes. In the present work, the solid-state reaction technique belongs to the physical method, has been used for the synthesis of materials. Instead of this, other chemical processes can also be applied for the preparation as well as for the investigation of characterizations of the nanomaterials. Stannic oxide-based nano-compounds, such as lanthanide stannate has been prepared by sol-gel, Pechini, solid-state reaction, complex precipitation, and hydrothermal methods [22]. Similarly, for the synthesis of stannate bases $\mathrm{Ln}_{2} \mathrm{Sn}_{2} \mathrm{O}_{7}$, numerous procedures have been proposed such as Pechini, aerosol pyrolysis, solidstate, hydrothermal way, and aerosol pyrolysis [23].Previously, combustion, co-precipitation, reverse micelle, sol-gel, solid-state processes have been established for the fabrication of $\mathrm{BaSnO}_{3}$ [24]. Moreover, the rare-earth-doped cerium oxide compounds have been formed through mechanochemical, Pechini, combustion, co-precipitation, and solvothermal techniques [25]. Likewise, for the synthesis of $\operatorname{Pr}_{2} \mathrm{Ce}_{2} \mathrm{O}_{7}$ nanostructures, efficient and novel fuel and banana extract has been utilized through a facile and eco-friendly technique at mild condition [26]. Perovskite type of alkaline earth stannates having a standard formula of $\mathrm{MSnO}_{3}$ (where $\mathrm{M}=\mathrm{Ca}$, $\mathrm{Ba}, \mathrm{Mg}$, and $\mathrm{Sr}$ ) have attracted significant attention because of their extensive applications in several fields, like ferromagnets, photocatalysts, gas sensors, humidity sensor, thermally stable capacitors, ceramic dielectric bodies, anode materials used in lithium-ion batteries, and display phosphor matrix, over the previous few years. Freshly, the alkaline stannate-based perovskite compounds play an important role as potential transparent conducting oxides due to their wide optical band gap as a result they are used in optical apparatus, such as optical amplifiers and 
lasers (depending on electronic transitions of rare-earth ions). Similarly, the luminescence properties of the substituted earth stannates have also been explored in recent times [27-29]. As a result of unique size as well as shape-dependent properties, inorganic compounds of uniform size and shape are of fundamental attention and technological reputation [30]. Among all rare earth stannates, $\mathrm{CaSnO}_{3}$ (i.e., CSn) represents two crystalline systems: firstly an ordered system with hexagonal along with rhombohedral symmetry (having unit-cell parameters $\left(a=5.487 \mathrm{~A}^{\circ}, c\right.$ $\left.=15.287 \mathrm{~A}^{\circ}\right)$ as well as $\left(a=6.000 \mathrm{~A}^{\circ}, \alpha=54.42^{\circ}\right)$ respectively); and secondly a perovskite structure with orthorhombic phase (having space group Pbnm, with lattice parameters $a=$ $\left.5.5142 \mathrm{~A}^{\circ}, b=5.6634 \mathrm{~A}^{\circ}, c=7.88162 \mathrm{~A}^{\circ}\right)$. This is also known as a wide band gap semiconductor having a band gap of around $4.4 \mathrm{eV}$ [31]. $\mathrm{CaSnO}_{3}$ is a nice illustration of the correlated electronic system which declines the conduction band (CB) gap by increasing octahedral tilting. The addition of $\mathrm{CaSnO}_{3}$ in the parent compound BNT has certain advantages such as high reactivity, high surface area, and it also reduces the synthesis time as well as the temperature [32]. In recent years, selenites have been studied extensively because of their interesting ferroelectric properties. Due to this reason, we added calcium selenites $\left(\mathrm{CaSeO}_{3}\right)$ and calcium stannate $\left(\mathrm{CaSnO}_{3}\right)$ in equal ratios to the parent BNT compound [33]. Alkaline earth selenites with the common formula $\mathrm{MSeO}_{3}(\mathrm{M}=\mathrm{Ba}, \mathrm{Ca}, \mathrm{Sr}, \mathrm{Mg})$ are widely used in different production fields like tele-mechanics and electronics for the manufacturing of semiconductors and luminophores. According to scientific and practical viewpoints, selenium as well as its compounds are more important as selenium with +4 oxidation states, have multiple practical applications in different fields like in agriculture as repellants and fertilizers, in case of organic synthesis as catalysts and they are also used as precursors for the synthesis of the stoichiometric composition of pure selenides having interesting semiconductor behavior. Furthermore, the selenites are also used as an intermediate product of purification and production of selenium and as pigments designed for glasses as well as enamels similarly as antioxidants in the field of medicines in recent times [34]. In the case of alkaline earth selenites when suitable solutions are added at the neutral point, a white powder of high value of the refractive index is formed. $\mathrm{CaSeO}_{3}$ is a wideband gap semiconductor with band gap of $4.43 \mathrm{eV}$ and it shows monoclinic structure with space group $\mathrm{P} 21 / \mathrm{n}$ and lattice parameters $(a=6.402 \AA, b=6.791 \AA, c=6.681 \AA, \beta$ $=102.78^{\circ}$ ) [35]. In the case of selenium, it is experimentally detected that its coordination number varies from 4 to 3 and consequently the oxygen-rich selenate phase is converted to 
oxygen deficiency selenite phase. As a result, it affects the network structure (in the case of glass) and other physical properties, which shows the importance of selenites in different scientific challenges [36]. Another cause to introduce $\mathrm{SeO}_{2}$ is that it reduces the melting temperature and therefore improves the optical properties in case glass compositions. Selenium (Se) ion has a very high value of polarizability hence at room temperature the glass containing $\mathrm{SeO}_{2}$ displays a high value of ion conductivity of the order of $10^{-3}-10^{-4} \mathrm{~S} / \mathrm{cm}$ [37]. Including all the above advantages, to improve the physical as well as electrical properties of the parent $\left(\left(\mathrm{Bi}_{0.5} \mathrm{Na}_{0.5}\right) \mathrm{TiO}_{3}\right)$ compound an equivalent amount of $\mathrm{CaSnO}_{3}$ and $\mathrm{CaSeO}_{3}$ is added to it in this present work.

\section{Compound Synthesis and characterization}

The polycrystalline materials of $\mathrm{CaSnO}_{3}-\mathrm{CaSeO}_{3}$ modified $\left(\mathrm{Bi}_{0.5} \mathrm{Na}_{0.5}\right) \mathrm{TiO}_{3}$ with a general chemical formula $(1-2 \mathrm{x})\left[\left(\mathrm{Bi}_{0.5} \mathrm{Na}_{0.5}\right) \mathrm{TiO}_{3}\right]+\mathrm{x}\left(\mathrm{CaSnO}_{3}\right)+\mathrm{x}\left(\mathrm{CaSeO}_{3}\right)$ i.e., (BNT-CSn-CSe) with different concentrations $(\mathrm{x}=0,0.05,0.1,0.15)$ were fabricated through cost effective solid state reaction method. The stoichiometric ratios of analytical grade (i.e., high purity) of oxides and carbonates (as specified in Table-1) were measured using a digital balance (Mettler Type: New Classic MF; Model: ML204/A01) accurate up to four decimal places.

Table 1: List of chemical reagents with chemical formula, purity, and suppliers, used as raw materials.

\begin{tabular}{|c|c|c|c|}
\hline Chemical Reagents & Chemical formula & purity & Suppliers \\
\hline Bismuth Oxide & $\mathrm{Bi}_{2} \mathrm{O}_{3}$ & $99.0 \%$ & Loba Chemie Pvt. Ltd. \\
\hline Sodium carbonate & $\mathrm{Na}_{2} \mathrm{CO}_{3}$ & $99.5 \%$ & Central Drug House Pvt. Ltd. \\
\hline Calcium carbonate & $\mathrm{CaCO}_{3}$ & $99.9 \%$ & Loba Chemie Pvt. Ltd. \\
\hline Titanium oxide & $\mathrm{TiO}_{2}$ & $99.5 \%$ & Loba Chemie Pvt. Ltd. \\
\hline Stannic oxide & $\mathrm{SnO}_{2}$ & $99.9 \%$ & Loba Chemie Pvt. Ltd. \\
\hline Selenium dioxide & $\mathrm{SeO}_{2}$ & $>98 \%$ & Merck-Schuchardt \\
\hline
\end{tabular}

These raw materials were mixed thoroughly in the dry-grinding mode for $1 \mathrm{~h}$ followed by wet grinding using methanol for $4 \mathrm{~h}$ by agate mortar and pestle to obtain homogeneous mixtures of nanoscale size. The calcination of the prepared mixtures was carried out at an optimized temperature of $925^{\circ} \mathrm{C}$ by using covered alumina crucibles in a high-temperature muffle furnace with a $3{ }^{\circ} \mathrm{C} / \mathrm{min}$ heating rate for $4 \mathrm{~h}$. At the time of calcination, methanol (with boiling point 64.7 
${ }^{\circ} \mathrm{C}$ ) used in wet grinding, was completely evaporated and a cylindrical lump of the calcined compounds was obtained. The calcinations, as well as grinding processes, were repeated, usually till the development of the compounds. Room-temperature X-ray diffraction (XRD) patterns of the compounds were recorded by the X-ray diffractometer (Rigaku Mini flex, Japan) for looking at the phase formation and preliminary structural analysis. The XRD spectrum of the compounds was obtained with $\mathrm{CuK} \alpha$ (wavelength $\lambda=1.5405 \AA$ ) in a wide range of Bragg angles $2 \theta\left(20^{\circ} \leq 2\right.$ $\theta \leq 80^{\circ}$ ) at $3^{\circ} / \mathrm{min}$ scan rate. The homogeneous and fine powders were then cold-pressed into cylindrical pellets of $10 \mathrm{~mm}$ diameter and 1-2 mm thickness by $\mathrm{KBr}$ hydraulic press under an axial pressure of $4 \times 10^{6} \mathrm{Nm}^{-2}$ by adding PVA (polyvinyl alcohol) as a binder.

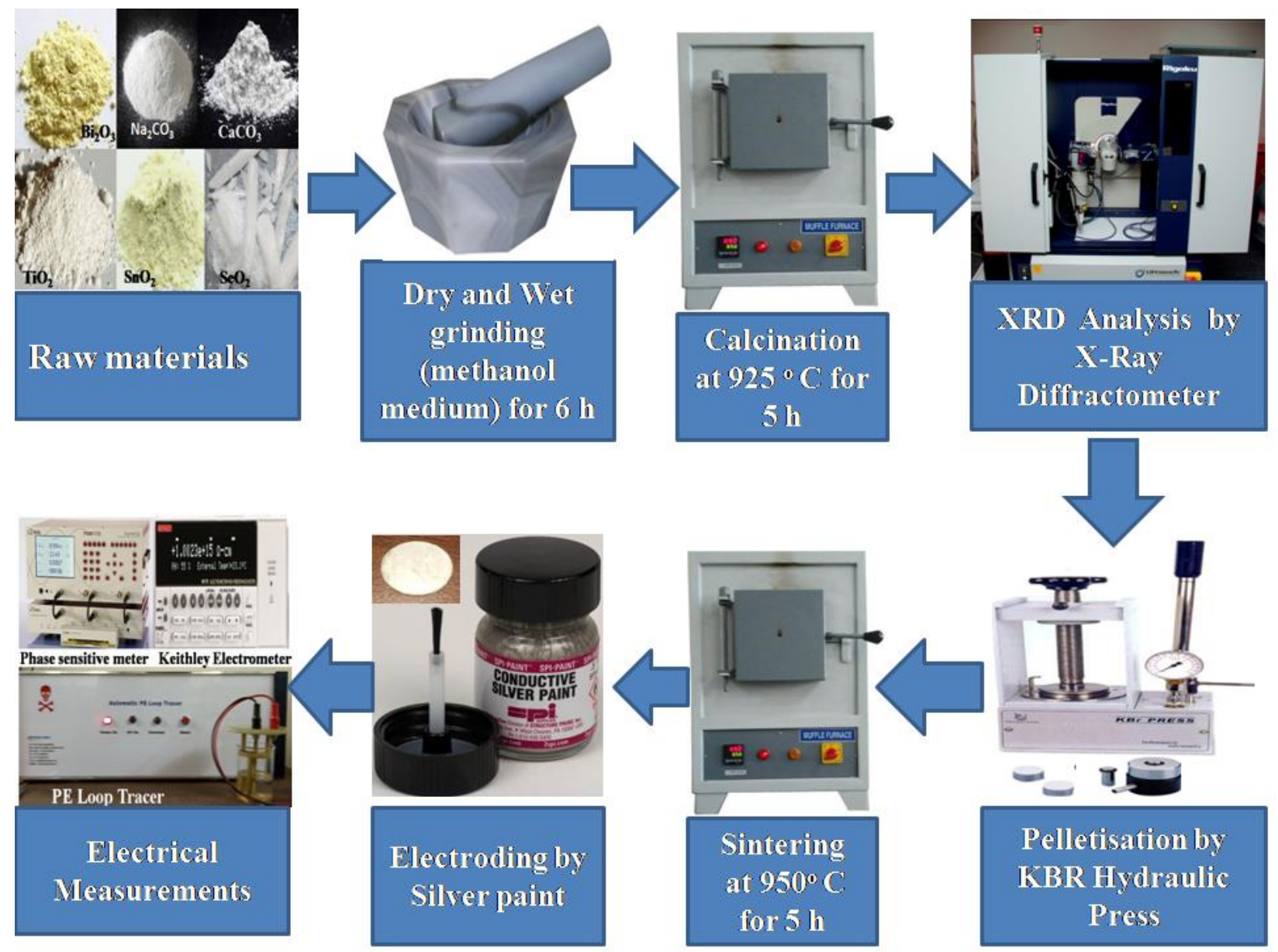

Figure.1 Schematic diagram of synthesis through solid-state reaction method and characterization of (1-2x) BNT- $x$ CSn- $x$ CSe compounds with different percentage $(x=0$, 0.05, 0.1, 0.15). 
The synthesized pellets were then sintered at an optimized temperature of $1000^{\circ} \mathrm{C}$ for $4 \mathrm{~h}$ in an alumina boat and then cooled down to room temperature slowly to prepare hard and dense pellets. The sintered pellets were polished by using fine sandpaper to make the surface parallel and smooth. After this, an electrode was carried out on both surfaces of the pellets by high purity conducting silver paint of Alfa Aesar and heated at $150{ }^{\circ} \mathrm{C}$ for $4 \mathrm{~h}$ to study electrical properties. Different electrical measurements of the samples (i.e., dielectric, impedance, conductivity, and modulus) were obtained with the impedance analyzer (phase-sensitive meter PSM 1735, N4L), with a sample holder, operating in a wide frequency range from $1 \mathrm{kHz}$ to $1 \mathrm{MHz}$ at different temperatures $\left(25^{\circ} \mathrm{C}-400{ }^{\circ} \mathrm{C}\right)$. The PE loop tracer $(\mathrm{M} / \mathrm{S}$ Marine India) was used to examine the ferroelectric behavior of the materials. The J-E characteristics of the studied samples of all percentages were measured at room temperature by using a programmable electrometer (Keithley, model 6517B). The schematic diagram of the solid-state synthesis and characterization of the studied compounds was provided in Figure 1.

\section{Results and discussions}

\subsection{Structural analysis}




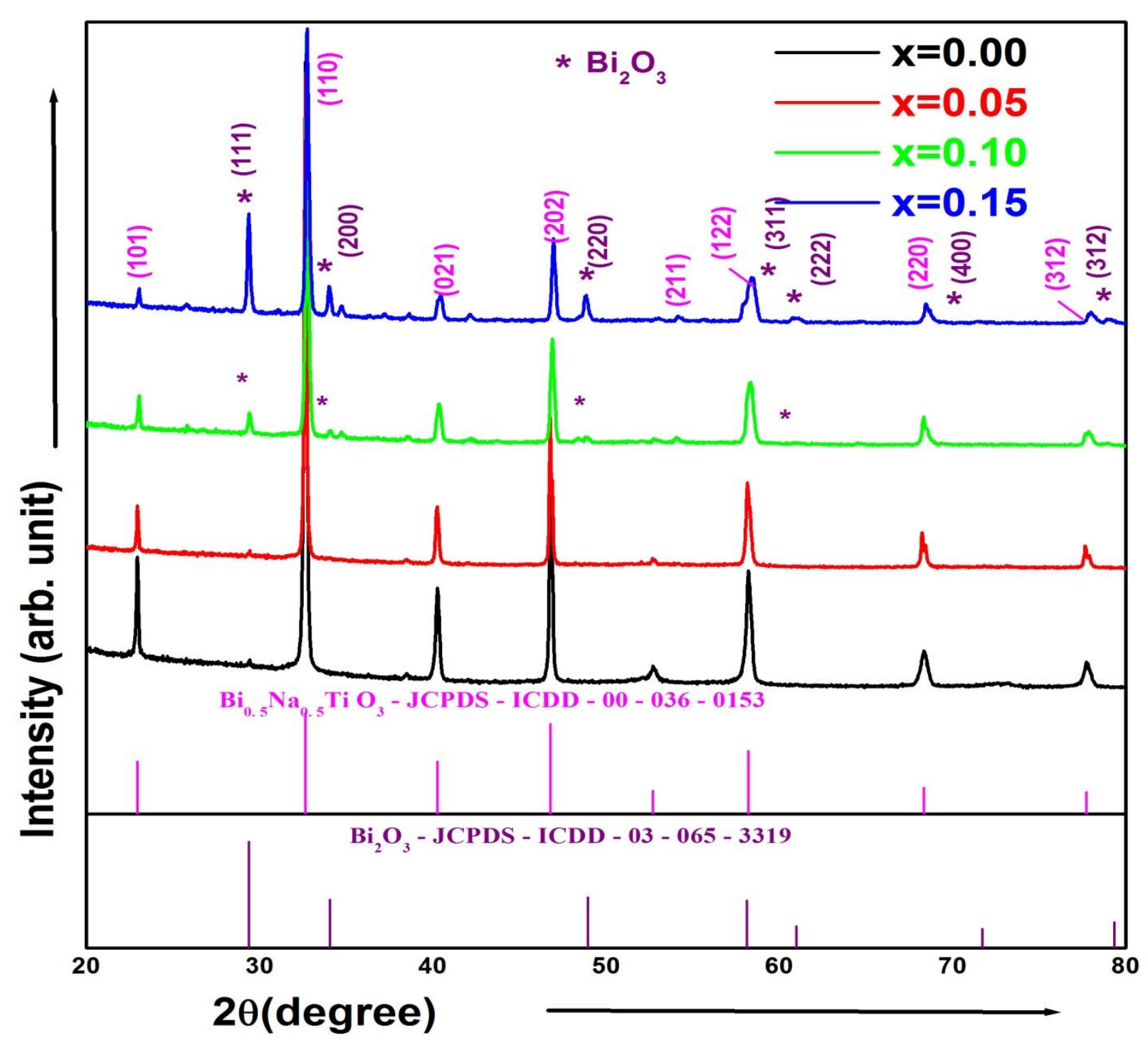

Figure 2(a): The X-ray diffraction patterns of (1-2x) BNT- $x$ CSn- $x$ CSe compounds with $(\mathrm{x}=0,0.05,0.1,0.15)$.

The preliminary structural study of the materials by using XRD data determines the degree of crystallinity as well as the phase purity of the compounds. Figure 2(a) displays the room temperature XRD spectra of the calcined BNT-CSn-CSe ceramics with various concentration $(x=0,0.05,0.1,0.15)$. There are numerous sharp peaks in the XRD spectrum, different from those of the constituents, confirm the formation of a new compound with very small intensity impurity peaks (secondary phases), as marked by an asterisk with $\mathrm{x}=0.1$ and 0.15 corresponding to $\mathrm{Bi}_{2} \mathrm{O}_{3}$. All the characteristic peaks of the materials were attempted to index in the rhombohedral structure with the reported lattice parameters: $\mathrm{a}=5.476 \mathrm{~A}^{\circ}$ and $\mathrm{c}=6.778 \mathrm{~A}^{\circ}$ of 
[( $\left.\left.\mathrm{Bi}_{0.5} \mathrm{Na}_{0.5}\right) \mathrm{TiO}_{3}\right]$ in accordance to JCPDS database with ICDD (International Centre for Diffraction Data) card number 00-036-0340). Similarly, the extra peaks are also indexed in cubic phase with card no.03-065-3319). For getting complete structural evidence of the synthesized materials, Rietveld refinements were done by the use of Maud software as represented in Figure 2(b).

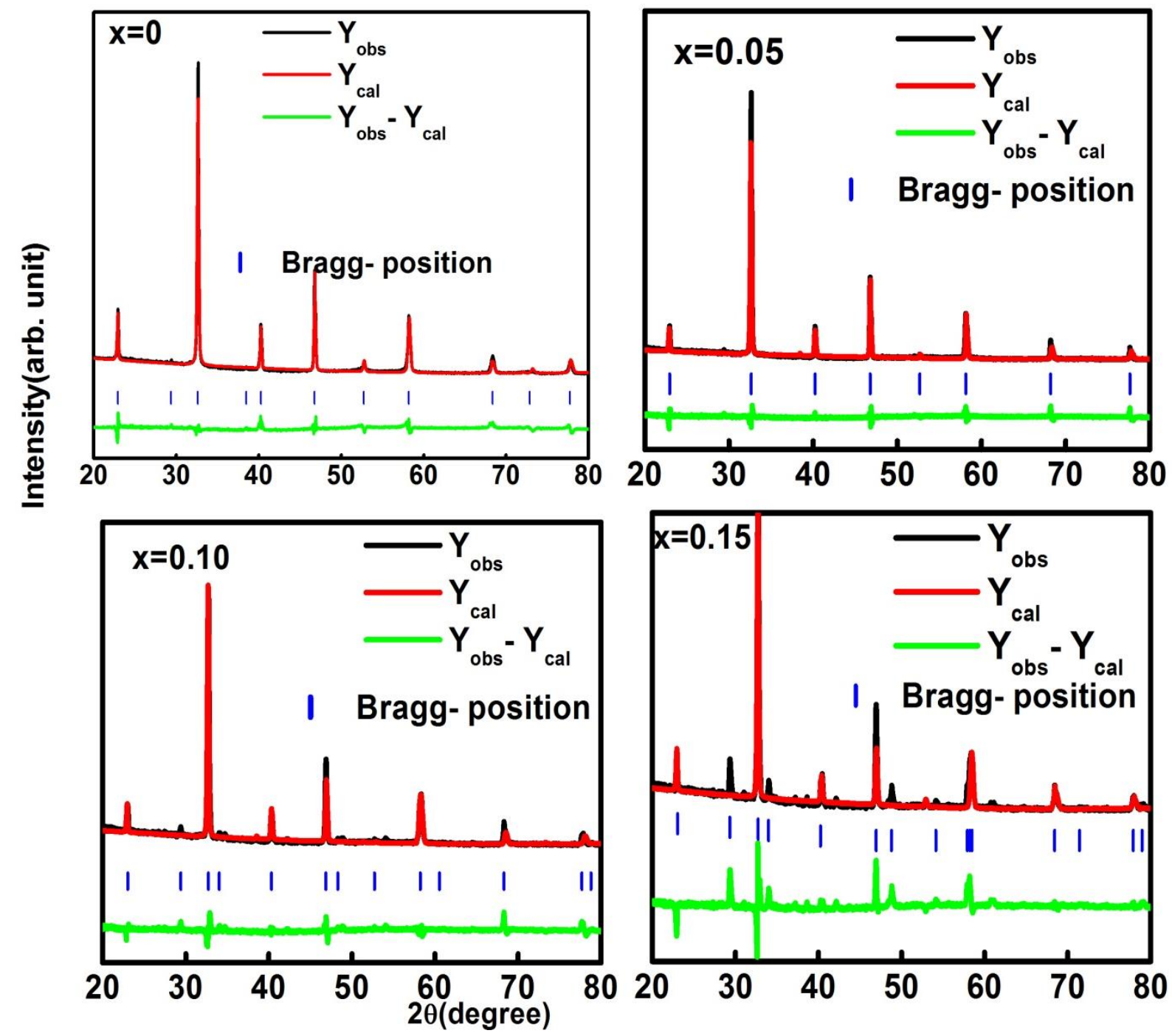

Figure 2(b): Rietveld refinement results of $(1-2 x)$ BNT- $x C S n-x C S e$ ceramics with $(x=0$, $0.05,0.1,0.15)$ at room temperature.

The refinements were performed on the experimentally observed diffraction peaks of the material BNT-CSn-CSe of rhombohedral crystal symmetry (with space group R3c) by crystallographic information file (CIF: NIMS_MatNavi_4295277669_1_2). This technique 
maximizes the agreements between the calculated and experimentally observed diffraction patterns. In this figure for all four compositions, the black and red solid lines signify the observed and calculated results, and the small deviation in between them is represented by the green solid line, whereas the position of Bragg's positions is shown by the blue line like symbols. The small fluctuations in the green line at different diffraction peaks due to a mismatch of intensities confirm the exactness of the structural refinement. The different reliability/fitting parameters such as $R_{w p}$ (weighted profile index), $R_{\exp }$ (expected weighted profile index), $R_{b}$ (Bragg R index), and goodness of fit (gof) obtained from the refinements are listed in table 2 and defined by equations given below.

$R_{w p}=\left[\frac{\sum\left(w_{i}\left(y_{i}(o b s)\right)-\left(\frac{1}{c}\right) y_{i}(c a l)^{2}\right)}{\sum w_{i}\left(y_{i}(o b s)\right)^{2}}\right]^{\frac{1}{2}}$

$R_{\exp }=\frac{\sum\left|\left(y_{i}(o b s)\right)-\left(\left(\frac{1}{c}\right) y_{i}(c a l)\right)\right|}{\Sigma y_{i}(o b s)}$

$R_{b}=\frac{\sum\left|\left(I_{k}(o b s)\right)-\left(I_{k}(c a l)\right)\right|}{\sum\left(I_{k}(o b s)\right)}$

$\sigma=\frac{R_{w p}}{R_{e x p}}$

Here the summation is spread over all points present in the diffraction spectrum and $y_{i}$ is the intensity for $\mathrm{i}^{\text {th }}$ step for observed and calculated data [38,39]. In Rietveld refinement, the goodness of fit index (gof) is responsible for errors in the model for the intensities, and for better refinements, this index would be less than 2 [40]. The crystallite size,(D) of the synthesized material is determined by the use of the Scherrer equation,

$$
D=\frac{k \lambda}{\beta_{1 / 2} \cos \theta_{h k l}}
$$

Where $\mathrm{k}=0.94$ for a rhombohedral structure called the anisotropic constant, $\lambda$ is the wavelength of $\mathrm{CuK} \alpha$ radiation equal to $1.5405 \AA, \beta_{1 / 2}$ is the FWHM (full width at half maximum) of the diffraction peak, and $\theta_{h k l}$ is the Bragg's angle of diffraction from hkl plane [41, 42]. The average 
crystallite sizes for all four concentrations i.e., $\mathrm{x}$ varies from 0 to 0.15 are calculated from the above formula are given in table 2.

Table 2 : Lattice parameters and reliability parameters of BNT-CSn-CSe ceramics with $(\mathrm{x}=0$, $0.05,0.10,0.15)$.

\begin{tabular}{|c|c|c|c|c|c|c|c|c|}
\hline \multirow{2}{*}{$\begin{array}{c}\text { Composition } \\
\text { (x) }\end{array}$} & \multirow{2}{*}{$\begin{array}{l}\text { Crystal Structure } \\
\text { and } \\
\text { Space group }\end{array}$} & \multicolumn{2}{|c|}{ Lattice Parameters $(\AA)$} & \multicolumn{4}{|c|}{ Reliability Parameters (\%) } & \multirow{2}{*}{$\begin{array}{l}\text { Crystallite } \\
\text { Size (nm) }\end{array}$} \\
\hline & & $\mathrm{a}$ & $\mathrm{c}$ & $\mathrm{R}_{\mathrm{w}}$ & $\mathrm{R}_{\mathrm{b}}$ & $\mathrm{R}_{\exp }$ & gof & \\
\hline 0 & \multirow{4}{*}{ Rhombohedral } & 5.476 & 13.462 & 15.17 & 14.11 & 10.31 & 1.47 & 58 \\
\hline 0.05 & & 5.488 & 13.413 & 15.24 & 14.56 & 10.65 & 1.43 & 63 \\
\hline 0.10 & & 5.477 & 13.373 & 13.95 & 11.15 & 7.08 & 1.97 & 62 \\
\hline 0.15 & & 5.459 & 13.417 & 14.59 & 12.45 & 8.63 & 1.69 & 64 \\
\hline
\end{tabular}

\subsection{Dielectric study}

In recent years, the study of dielectric behavior including dielectric parameters (dielectric constant as well as dielectric loss) of different ceramics is very significant due to their wide range of potential applications in several fields like energy storage devices as well as ferroelectric industries. For a capacitor, the dielectric constant $\left(\varepsilon_{\mathrm{r}}\right)$ calculates its charge storing capacity while dielectric loss (loss tangent $(\tan \delta)$ ) is considered as the fraction of energy dissipated to the total energy store in it. In other words, the dielectric constant (relative permittivity) is usually determined as the ratio between the capacity of a condenser filled with a certain dielectric material and the capacity of a similar condenser in space without the dielectric compound. It is expressed as the general formula,

$\varepsilon_{r}=\frac{C}{C_{0}}$

Where $\varepsilon_{\mathrm{r}}$ the dielectric constant, $\mathrm{C}$ is nothing but the parallel capacitance $\left(\mathrm{C}_{\mathrm{p}}\right)$ (obtained from the LCR data), and $\mathrm{C}_{0}$ is defined as, 
$C_{0}=\frac{\varepsilon_{0} A}{d}$

Where $\varepsilon_{0}$ is permittivity in free space and $A$ and $d$ are the area and thickness of the sintered pellet respectively. Similarly, at a certain frequency dielectric loss ( $\tan \delta)$ of the material acting as a capacitor is determined as the ratio of the real part $\left(Z^{\prime}\right)$ of the complex impedance $(Z)$ to its imaginary part (Z") i.e.,

$\tan \delta=\frac{Z^{\prime}}{Z^{\prime \prime}}$

The large value of $\tan \delta$ carries large dielectric absorption. The capacitance of a good dielectric sample changes slowly with frequency, therefore, $\tan \delta$ can be evaluated from the rate of change of capacitance. However, these dielectric parameters mainly depend on the structure, components along with frequency and temperature like experimental conditions and provide knowledge about different polarization processes present in the material.

\subsubsection{Effect of frequency on dielectric study}

The variation of dielectric constant and dielectric loss with the frequency of studied samples BNT-CSn-CSe with various compositions $(\mathrm{x}=0,0.05,0.1,0.15)$ in a wide range of temperature starting room temperature $\left(25^{\circ} \mathrm{C}\right)$ to $400{ }^{\circ} \mathrm{C}$ is given in Figure 3(a) and 3(b) respectively. Figure 3(a) is based on various types of polarization processes. From this figure, the value of the dielectric constant is high in the low-frequency region, and with the rise in frequency the value decreases and this is the general tendency of dielectric materials. 


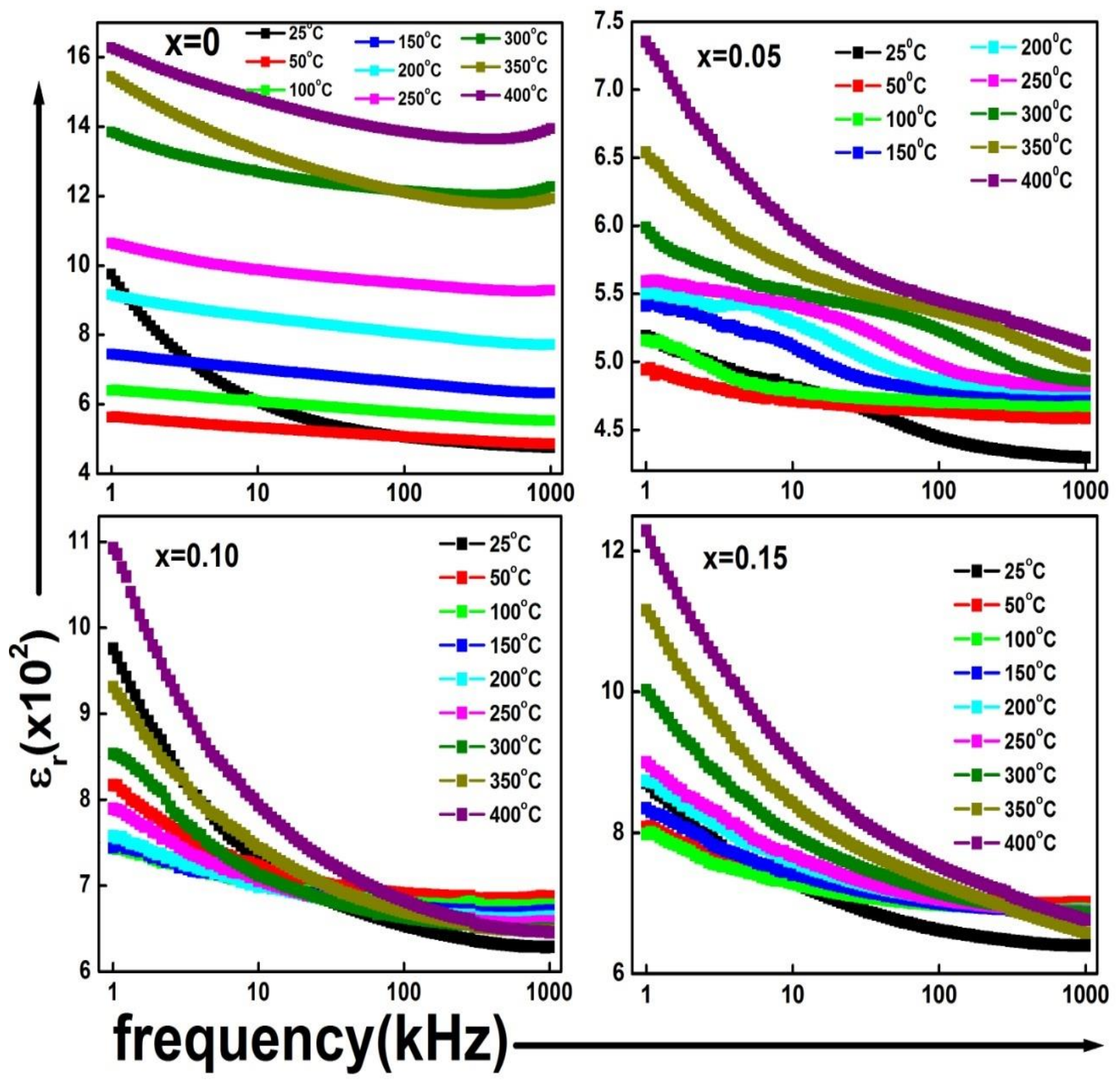

Figure 3(a): Frequency dependence of dielectric constant of (1-2x) BNT- x CSn $-x$ CSe compound at different temperatures $\left(25^{\circ}-400^{\circ} \mathrm{C}\right)$ with $(x=0,0.05,0.1,0.15)$.

The cause behind this nature is that at low-frequency region the existence of all four types of polarization processes (electronic, ionic, orientation and space charge) are found, and they provide the total polarization, hence dielectric constant retains large in this region. When we raise the frequency (above $10 \mathrm{kHz}$ ), space charge polarization decreases and become deactivate because of the inertia of the fast-moving ions (dipoles) towards the boundary, and having a small 
value of dielectric constant [43]. The reduction of $\varepsilon_{\mathrm{r}}$ value with raise in frequency is also due to the transformation of electrons between $\mathrm{Ti}^{3+}$ and $\mathrm{Ti}^{4+}$ at the octahedral site and thus can't detect the switching of ac field at larger frequency. The value of $\varepsilon_{\mathrm{r}}$ decreases quickly in the region of low frequencies, and slowly in the high-frequency side. In this case, if we take $x=0.15$, the plot for an instance, we find the value of $\varepsilon_{\mathrm{r}}$ decreases from 12.3 to 8 at $1 \mathrm{kHz}$ and from 7.8 to 6.3 at 1 $\mathrm{MHz}$ and the same thing happens for all four compositions.

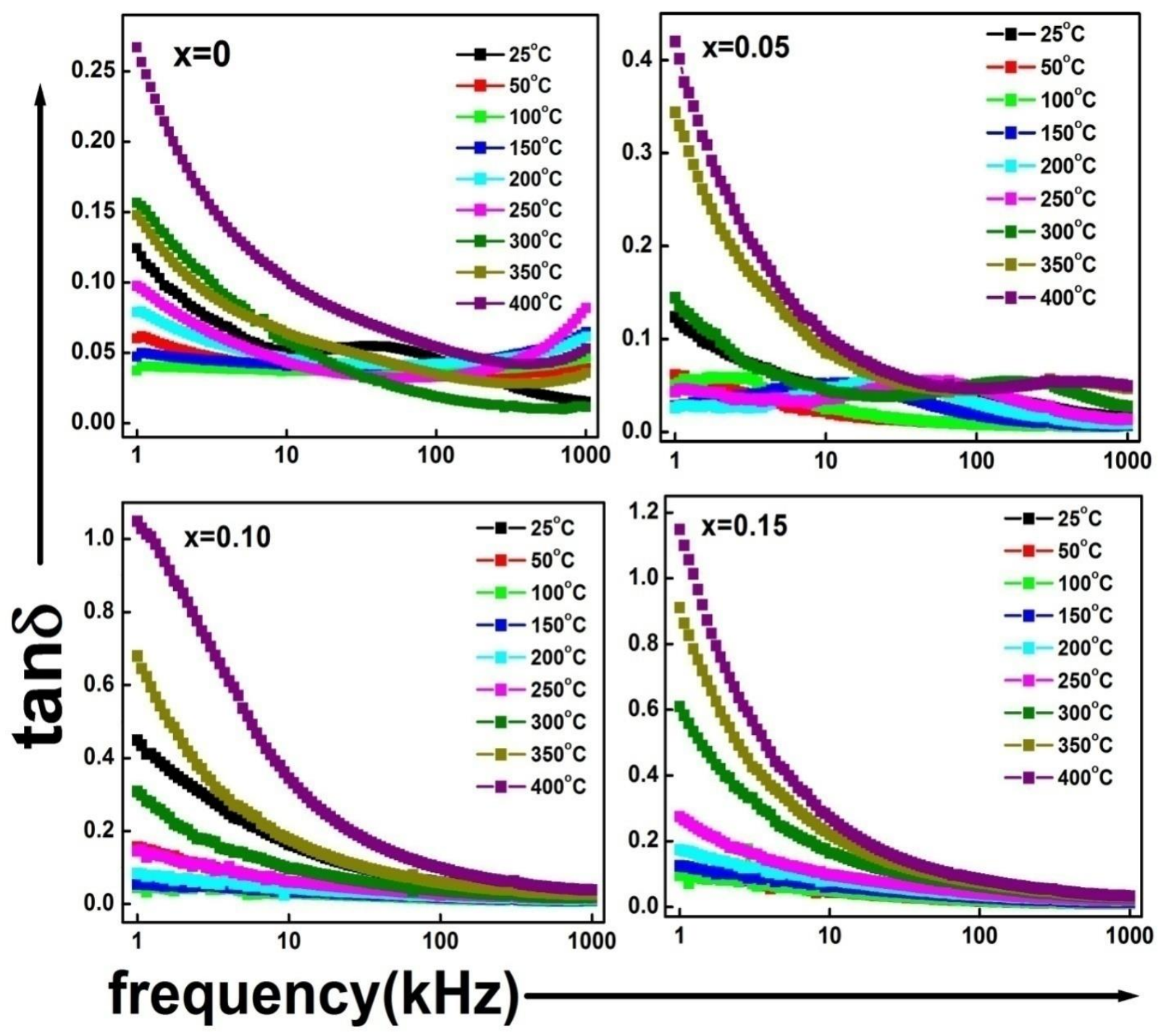

Figure 2(b): Frequency dependence of dielectric loss of (1-2x) BNT- x CSn - x CSe compound at different temperatures $\left(25^{\circ}-400^{\circ} \mathrm{C}\right)$ with $(\mathrm{x}=0,0.05,0.1,0.15)$.

At low frequencies and high temperatures, the large value of the dielectric constant can be explained by Maxwell - Wagner polarization effect related to Koop's phenomenological twolayer model $[44,45]$. According to this model, it is assumed that the dielectric materials consist of 
two inhomogeneous layers (i.e., one conducting grains separated by a second thin layer of relatively poor conducting grain boundary). In the low-frequency region, the charge carriers are more active at grain boundaries, while in the high-frequency region, they are more active within the grains. More energy is required to move the charge carriers in the low frequency. Since the grain boundaries offer high resistance, the charge carriers accumulate at the grain boundary resulting in a high dielectric constant in this range. In the high-frequency range, the energy required to move the charge carriers is less due to low resistance offered by the grains. Therefore, the dielectric constant is also low at high frequency [46]. For $\mathrm{x}=0.05$ we observed around $10 \mathrm{kHz}$, a small anomaly is found at low temperature and for high temperature, its movement towards the right side is noticed. This small peak indicates at low frequency (below $10 \mathrm{kHz}$ ) the grain boundary dominates over grain and contributes to the polarization mechanism. From figure 3 (a) we found with an increase in the doping concentration the dielectric constant first decreases for $\mathrm{x}=0.05$ and further increases for larger concentration i.e., for $\mathrm{x}=0.10,0.15$. For the parent BNT compound, the maximum value of $\varepsilon_{\mathrm{r}}$ at $1 \mathrm{kHz}$ and $400{ }^{\circ} \mathrm{C}$ is found to be 1634 . When we substitute $\mathrm{CaSnO}_{3}$ and $\mathrm{CaSeO}_{3}$ in the parent compound this value is found to 740, 1099,1236 be for $\mathrm{x}=0.05,0.10,0.15$ respectively at the same frequency and temperature.

From figure 3(b) it is observed that the tangent loss (dielectric loss) follows the same trend as that of dielectric constant i.e., reduces with increase in frequency and has a constant value at large frequency. Moreover, the value of loss tangent also rises with temperature rise. The rate of increase of $\tan \delta$ in case low temperature is slow but in case of high temperature is comparatively sharper. The large amount of energy loss at low frequency is due to the passage of charge carriers to the grain boundary so, $\tan \delta$ has a high value in low frequency in contrast to the highfrequency region having low resistance. Conversely, tangent loss signifies the quantity of energy used by the applied field for the alignment of the dipole. There are some other factors also affect the tangent loss such as the size of the grain, oxygen vacancies, and DC conductivities [47]. In region of high temperature and low frequency the relatively high value of dielectric loss because the dominant contribution of electrical conductivity i.e.,

$$
\tan \delta=\frac{\sigma_{a c}}{\omega \varepsilon_{0} \varepsilon_{r}}
$$

Where $\omega$ is the angular frequency, $\varepsilon_{0}$ is the permittivity in free space and $\varepsilon_{\mathrm{r}}$ is the relative permittivity. It is visible from the graph that small anomalies are found in the loss tangent curves 
which are visible for $\mathrm{x}=0$ and 0.05 due to their relatively small value as compared to the other higher compositions. The anomalies (relaxation peaks) are established near about $100 \mathrm{kHz}$ and move towards the higher frequency for the higher temperature, hence specify the existence of the thermally activated dipolar relaxation in the compounds [48,49]. However, in the whole temperature as well as frequency range the tan $\delta$ possesses very small value for all four compositions, which makes the material appropriate for various device applications.

\subsubsection{Effect of temperature on dielectric parameters}

The variation of dielectric constant $\left(\varepsilon_{\mathrm{r}}\right)$ and dielectric loss $(\tan \delta)$ with temperature of the studied compounds BNT-CSn-CSe with all concentrations (i.e., $\mathrm{x}=0,0.05,0.10,0.15$ ) at different frequencies raising from $1 \mathrm{kHz}-1 \mathrm{MHz}$ is shown in Figure 3(c) and 3(d) respectively. It is seen from the graphs that the dielectric behavior of the studied compounds strongly depends upon frequency and temperature.
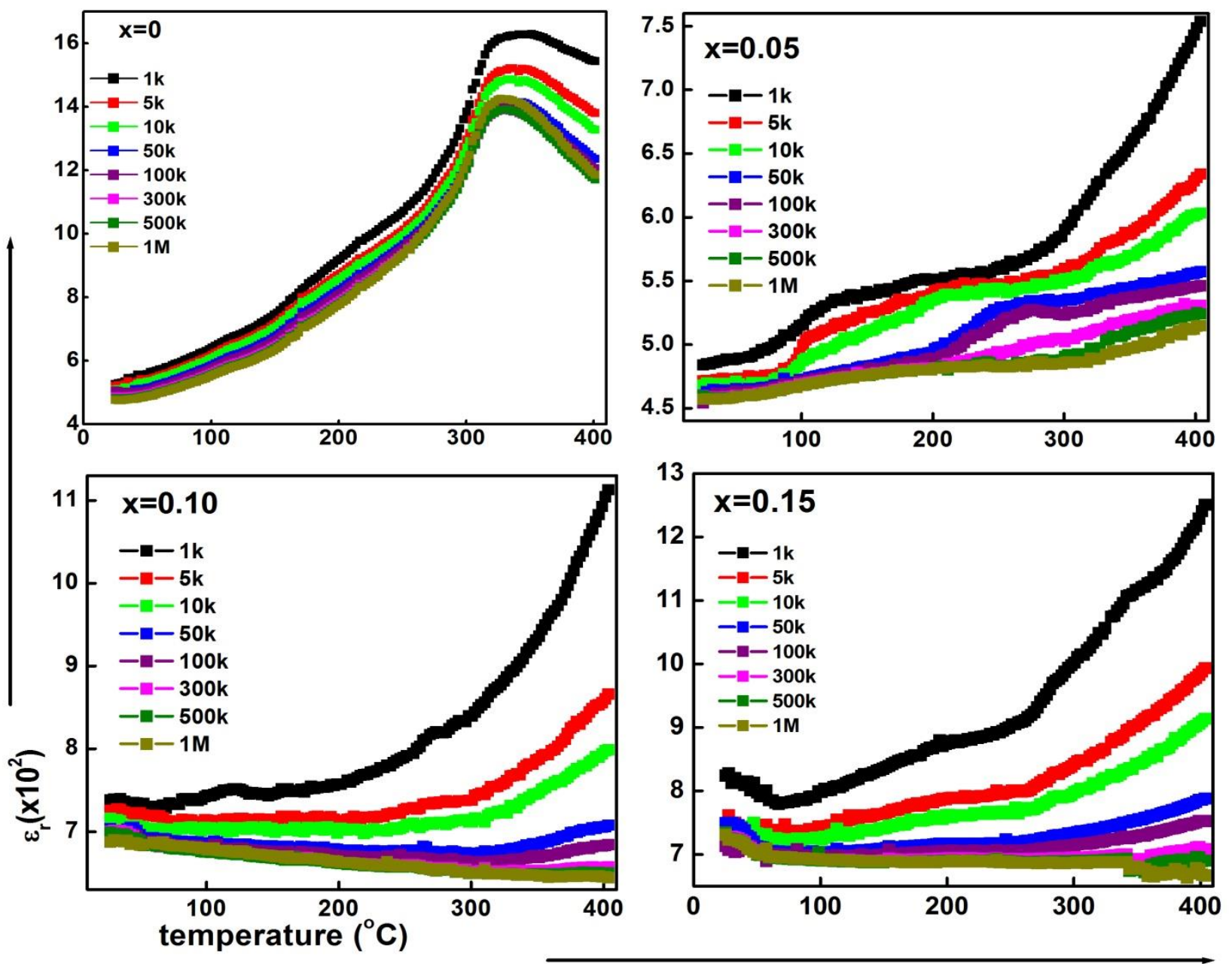
Figure 3(c): Temperature dependence of dielectric constant of (1-2x) BNT- x CSn - x CSe compound at different frequency $(1 \mathrm{kHz}-1 \mathrm{MHz})$ with $(\mathrm{x}=0,0.05,0.10,0.15)$.

The two dielectric anomalies (humps) in the dielectric constant versus temperature graphs are observed. The first hump is observed between room temperature $\left(25^{\circ} \mathrm{C}\right)$ and $210{ }^{\circ} \mathrm{C}$, which can be referred to as depolarized temperature $\left(\mathrm{T}_{\mathrm{d}}\right)$, whereas the second one is observed at a temperature higher than $320^{\circ} \mathrm{C}$ equivalent to the extreme value of the dielectric constant is called as maximum permittivity temperature $\left(T_{m}\right)$ [50]. Here $T_{d}$ is commonly considered as the transition temperature, where there is a phase transition from ferroelectric to anti-ferroelectric. Similarly, the maximum temperature $\left(\mathrm{T}_{\mathrm{m}}\right)$ corresponds to the transition from anti-ferroelectric to paraelectric phase. For common ferroelectric material, in the dielectric constant versus temperature graphs, both $\mathrm{T}_{\mathrm{d}}$ and $\mathrm{T}_{\mathrm{m}}$ coincide, where the observed transition from the ferroelectric to para-electric is called Curie temperature. But, this is not observed in the studied compounds [51]. In Figure 3(c), the noticeable rise of the dielectric constant curve at high temperatures and low frequency is essentially referred to as space charge polarization-related ionic conductivity [52]. As compared to the BNT compound, in its other compositions, expanded dielectric peaks are observed. This is because of the compositional variation and the disarrangement. As a result, the replacement of cations at one or more crystallographic positions of the lattice structure is expected. For example, the substitution at the A site (i.e., $\mathrm{Ca}^{2+}$ ) of the parent BNT compound of perovskite-type occupying a part of the $\mathrm{Bi}$ site, similarly $\mathrm{Sn}^{4+}$, and $\mathrm{Se}^{4+}$, occupy some of the $\mathrm{Ti}$ site [53]. In the current situation, by substituting in the parent compound, the relative permittivity (dielectric constant) value first falls for $\mathrm{x}=0.05$ and then rises for other high compositions $(x=0.1,0.15)$. In Figure $3(\mathrm{c})$ at $1 \mathrm{kHz}$, the dielectric constant reaches the maximum value of $1653,760,1120,1261$ for $\mathrm{x}=0,0.05,0.1,0.15$ respectively. 

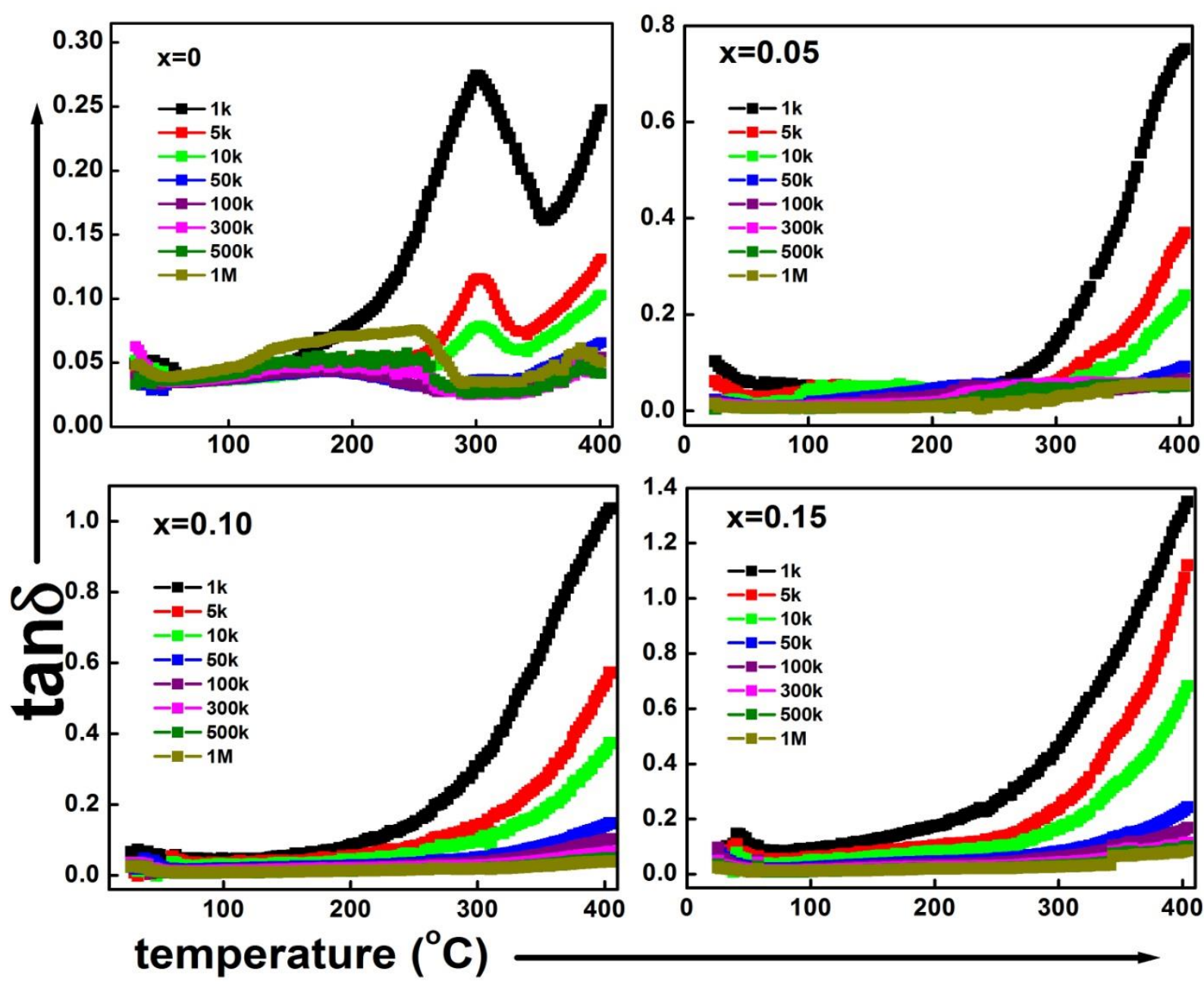

Figure 3(d): Temperature dependence of dielectric loss of (1-2x) BNT- x CSn - x CSe compound at different frequency $(1 \mathrm{kHz}-1 \mathrm{MHz})$ with $(\mathrm{x}=0,0.05,0.1,0.15)$.

The variation of $\tan \delta$ with temperature is shown in Figure 3(d). It is noticed in the graphs that $\tan \delta$ rises on raising the temperature for all compositions. This enhancement of $\tan \delta$ is prominent at high temperatures and low frequencies because of the high value of electrical conductivity; as a result, the motion of the electric dipoles becomes the maximum at the temperature. It is also noticed from the figure that in the low-temperature region the rising in $\tan \delta$ is slower and relatively faster in the high-temperature region, this is probably the presence of unknown defects such as oxygen vacancy along with the distribution of charge carriers in the sample [54]. The $\tan \delta$ possesses very low value up to $100^{\circ} \mathrm{C}$ for pure BNT and up to $150{ }^{\circ} \mathrm{C}$ for other higher concentrations ( $x=0.05,0.10,0.15)$. The loss tangent of the compounds exhibits relaxation peaks similar to the peak of the temperature-dependent dielectric constant. At the high temperature and low frequency, the loss tangent is high due to the conductivity factor owing to the presence of the 
alkali metal ion $\mathrm{Na}^{+}$and the existence of various oxidation states of the $\mathrm{Sn}$ ions [55]. In this graph, a small peak is noticed around $160^{\circ} \mathrm{C}$ for the pure BNT compound and the second peak is observed around $300{ }^{\circ} \mathrm{C}$, and these two peaks determine the presence of two transition temperatures of the compound. With the addition of $\mathrm{CaSnO}_{3}$ and $\mathrm{CaSeO}_{3}$ in the pure $\mathrm{BNT}$ compound, there is a slight increase in the loss tangent is observed, and have the maximum value of $0.27,0.75,1.04$ and 1.35 for $\mathrm{x}=0,0.05,0.10,0.15$ respectively at $1 \mathrm{kHz}$. However, these values are still small enough. The maximum value of the dielectric constant, as well as the small value of dielectric loss of the studied compounds, is very much applicable for different device applications.

\subsection{Impedance spectroscopy}

Complex impedance spectroscopy (CIS) is one of the most significant, non-destructive experimental methods for the collection of different electrical characters of the ceramics. Usually, the ceramic materials are non-homogeneous and consist of conducting grains separated by a relatively non-conducting grain boundary. Therefore, the CIS provides the complete information about the involvement of grain and grain boundary along with the electrode effect to the electrical behavior of the compounds and also separates the individual responses of these components based on relaxation time. The effects of the grain and grain boundary are represented by the electrical circuits where the parallel connection of resistance (R) and capacitance (C) are found. The relaxation process of the charge carrier is related to the orientation of dipoles and the movement of localized charge containing short-range motion and mobile charge containing wide range motion [56, 57]. Complex impedance $\mathrm{Z}$ consists of two components like real part or resistive component $\left(Z^{\prime}\right)$ and imaginary part or reactive component (Z") which are defined by the following equations [58].

$Z=Z^{\prime}+j Z^{\prime \prime}$

Where,

$Z^{\prime}=\frac{R}{1+(\omega \tau)^{2}}$

And

$Z^{\prime \prime}=\frac{\omega R \tau}{1+(\omega \tau)^{2}}$ 
Where $\mathrm{R}$ is the resistance, $\tau=\mathrm{RC}$ is the relaxation time, and $\omega=2 \pi \mathrm{f}$ is the angular frequency. The investigation of both the real and imaginary parts of the complex impedance at various frequencies as well as temperatures provides a thorough knowledge regarding the electrical properties.

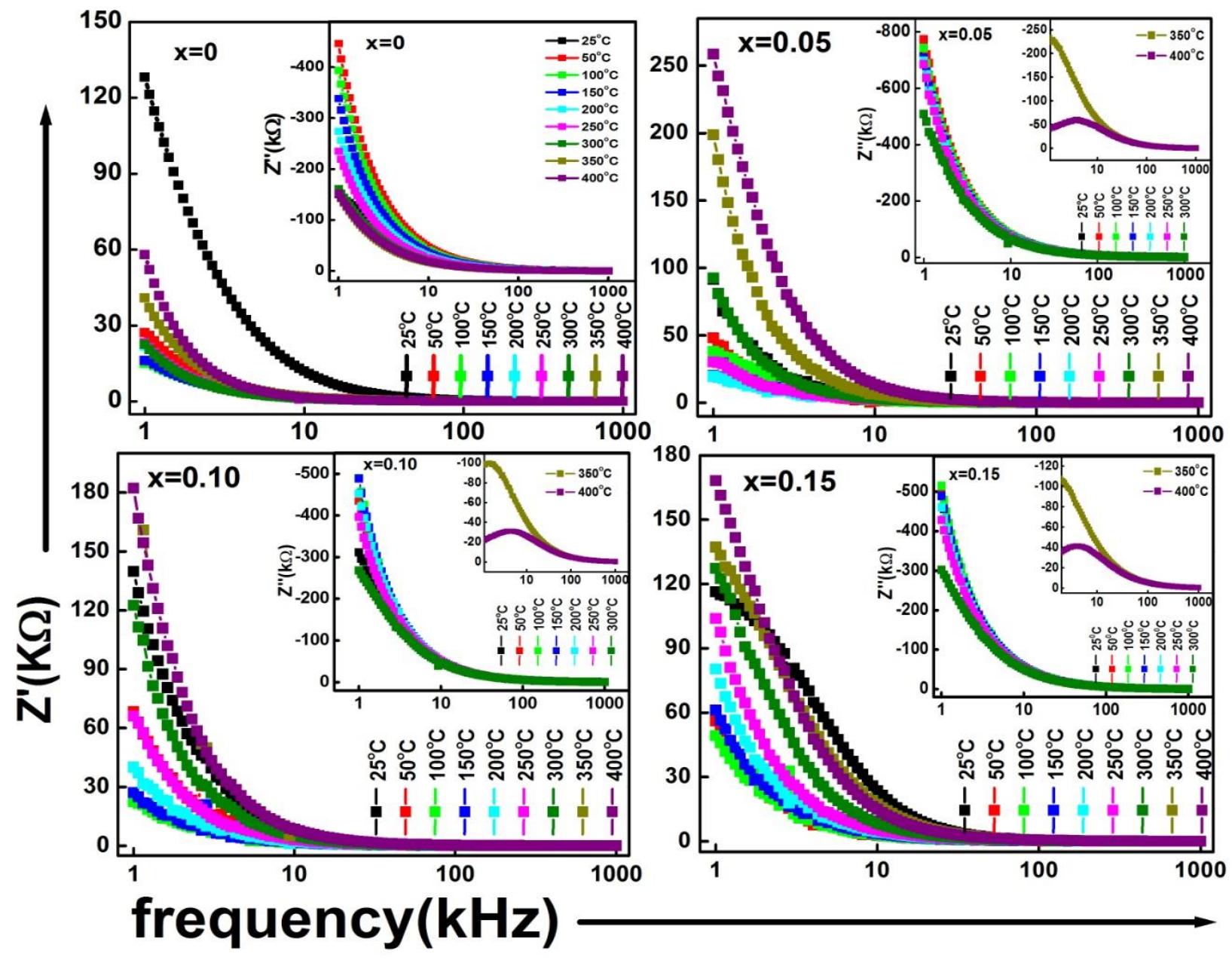

Figure 4(a): Frequency dependence of $Z^{\prime}$ and $Z^{\prime \prime}$ of (1-2x) BNT- $x$ CSn - x CSe compound at different temperatures $\left(25^{\circ}-400^{\circ} \mathrm{C}\right)$ with $(\mathrm{x}=0,0.05,0.1,0.15)$.

\subsubsection{Frequency dependence of $Z^{\prime}$ and $Z^{\prime \prime}$}

The frequency dependence of the real component of the complex impedance $(Z)$ of the studied compounds BNT-CSn-CSe at different concentrations $(\mathrm{x}=0,0.05,0.10,0.15)$ is shown in Figure 4(a). It has been noticed that with the rise in frequency and temperature, $Z^{\prime}$ value decreases monotonically and at last merges to a fixed value in the high-frequency region for all temperatures in the above four plots. The decrease of $Z^{\prime}$ strongly depends on frequency variation 
of ac conductivity and recommends the increase of ac conductivity with the rise in frequency. In the high-frequency region, whatever may be the temperature, all curves of the real part of impedance (i.e., $\left.Z^{\prime}\right)$ merge into a single line. This suggests the mechanism of temperature independence and the release of space charge, which is the main cause of enhancement of the ac conductivity by dropping the barrier property at high temperatures along with high frequency in the compounds [59]. In the low-frequency region (below $100 \mathrm{kHz}$ ) for all four plots, $\mathrm{Z}^{\prime}$ value decreases with a rise in temperature from $25{ }^{\circ} \mathrm{C}$ to $100{ }^{\circ} \mathrm{C}$. This represents the negative temperature coefficient of resistance (NTCR) behavior of the studied compound, which is a common character of semiconductor materials [60]. However, for the other high temperatures, this NTCR behavior reverses suddenly, and increases with an increase in temperature is known as the positive temperature coefficient of resistance (PTCR) properties of the compounds. This property of the compound specifies with the increase in temperature and the hopping probability of the ions/charge carriers decreases.

The inserted graphs of figure 4(a) depict the variation of imaginary part (Z") of the impedance with the frequency which is suitable for estimating relaxation frequency. From the figure for $\mathrm{x}=0.05,0.10,0.15$ concentrations there observed a peak (i.e., $\mathrm{Z}$ " achieves maximum value) shown in the inserted graph for the above doping concentration except for the parent one. In this case, it is visible only in higher temperature but for lower temperature, this peak remains in the frequency lower than $1 \mathrm{kHz}$ which is below our experimental range. The frequency for which the reactance component $\left(Z^{\prime \prime}\right)$ reaches the extreme value is known as relaxation frequency. For the $\mathrm{x}=0.15$ graph, it is noticed that when temperature increases from $350{ }^{\circ} \mathrm{C}$ to $400{ }^{\circ} \mathrm{C}$ there is a shifting of relaxation frequency is observed, which signifies that the relaxation process depends on temperature hence known as the thermally activated relaxation process of the substance. This relaxation phenomenon happens because of the effect of interface [61]. It is also prominent that with the increase in temperature the peak height decreases suggests that with the temperature rise, grain resistance reduces. This is because of the steady electrons (charges) at lower temperature and the creation of defects/oxygen vacancy at higher values of temperature [62]. 


\subsubsection{Nyquist plot}

Figure 4(b) depicts the Nyquist plot (Z" versus Z') of BNT-CSn-CSe at different temperatures $\left(25^{\circ} \mathrm{C}-400^{\circ} \mathrm{C}\right)$ in a wide range of frequency $(1 \mathrm{kHz}-1 \mathrm{MHz})$ for various concentrations $\mathrm{x}=0,0.05$, $0.1,0.15$. The impedance behaviors of the compounds are characterized by the development of semicircular arcs, and when the temperature changes the pattern of the arcs also changes. The degree of intercepts of the semicircular arc on the real part of the Z-axis, and its amount in the spectrum determines the type of electrical developments taking place in the compounds. The equivalent circuit elements represent the relationship between the arcs and the microstructure of the materials.

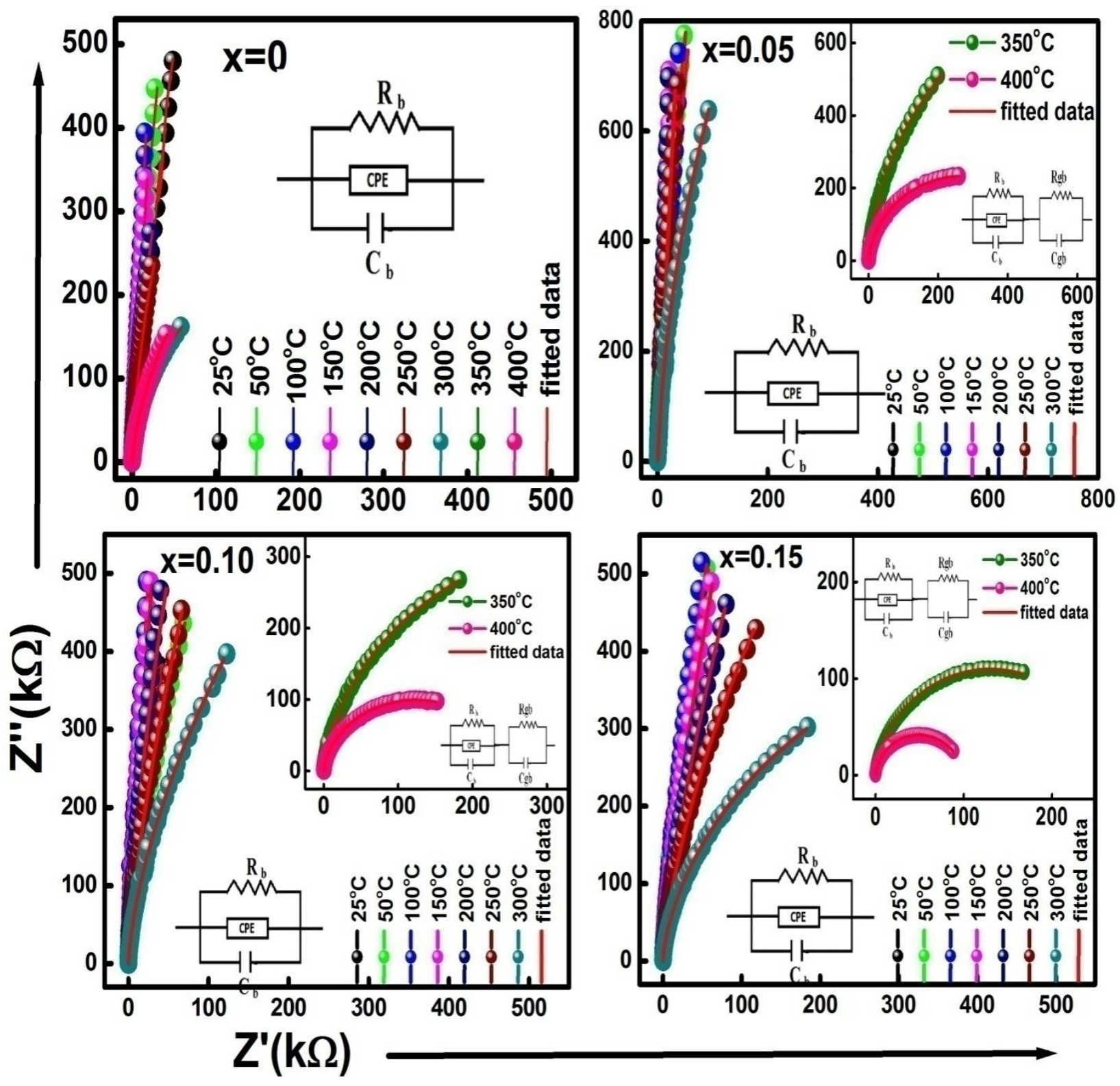


Figure 4(b): Nyquist plot of (1-2x) BNT- $x$ CSn - x CSe at at different temperatures (25$\left.400^{\circ} \mathrm{C}\right)$ with $(\mathrm{x}=0,0.05,0.1,0.15)$.

An equivalent circuit of series arrangement of parallel resistances (R) and capacitances (C) is used for each arc. In such a case, the capacitance represents space charge polarization and resistance represents the conductive path. The consecutive occurrence of the semicircle at high, medium, and low-frequency regions describes the effect of grain, grain boundary, and electrode effect respectively. The feature of the arc determines the category of relaxation phenomena in the system [63]. In the present case, only two semicircles are found, and out of which at low temperature the first one (representing grain) is observed, and with a further rise in temperature this gradually resolves into two overlapping semicircles (representing both grain and grain boundary) with their centers remain below the $Z^{\prime}$ axis representing non Debye type of relaxation mechanism usually called as a non-Debye type of relaxation. In the case of Debye type relaxation, a perfect semicircle is observed at high temperatures with its center lies on the Z' (real part of complex impedance) axis [64]. The removal of Debye type relaxation includes the constant phase elements (CPE) which are parallel to the RC circuit, in other words, the RC circuit along with CPE represents the non -Debye type of relaxation [65]. All the experimental data fitted by the equivalent circuit elements are carried out by using Z Simp Win software of version-2. Here in this graph, the solid symbol represents the experimental value of impedance and the red solid lines represent the fitted data for all four plots. 


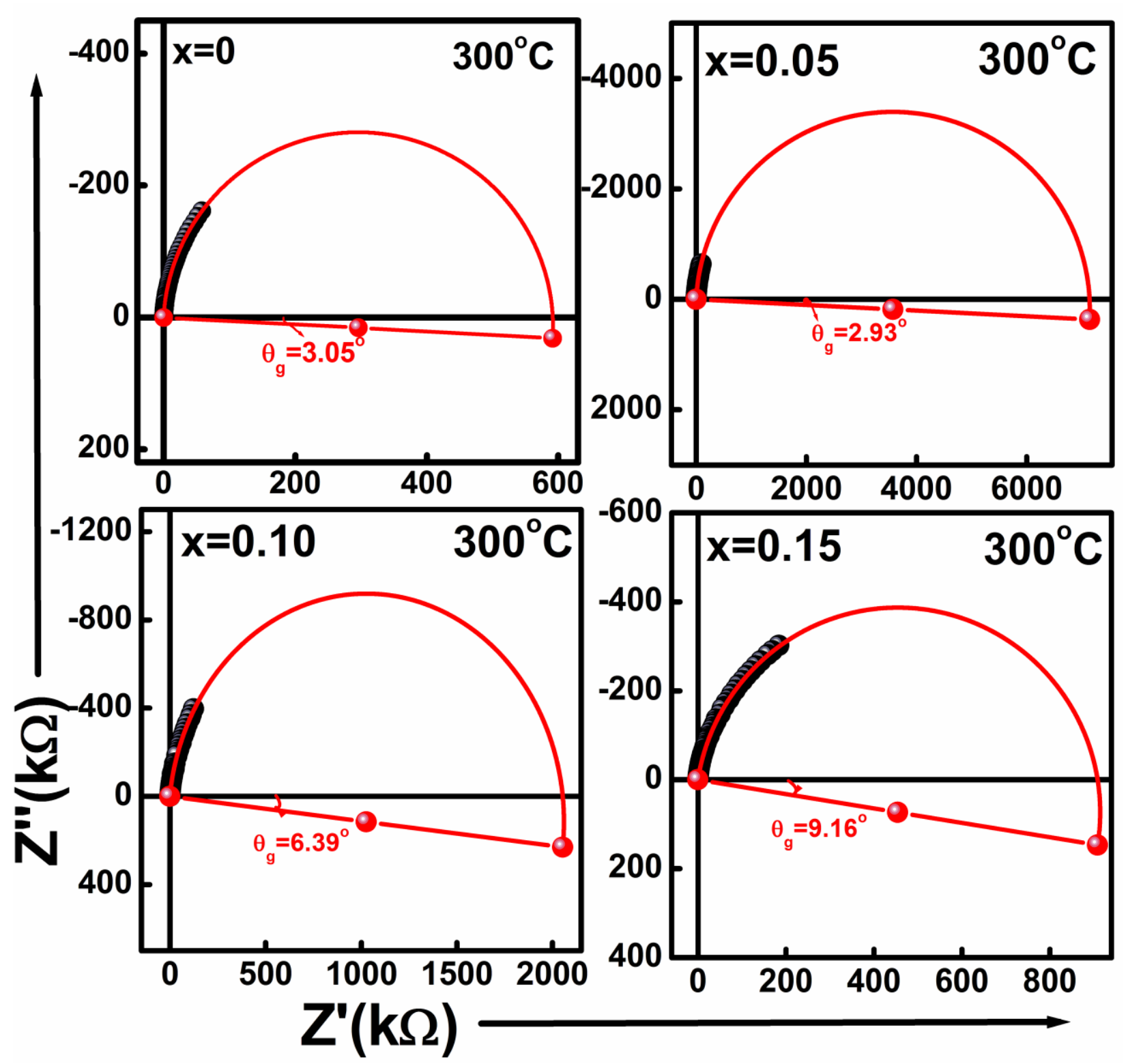

Figure 4 (c): The semicircle of Nyquist plot of (1-2x) BNT- $x$ CSn $-x$ CSe at 300 ${ }^{\circ}$ with different concentrations $(x=0,0.05,0.10,0.15)$.

For the parent compound $(\mathrm{x}=0$ composition) all the temperature curves propose a single depressed semicircular arc modeled by the equivalent circuit of (RQC) having parallel resistance as well as a capacitance with CPE connected at the center and parallel to them. This grain is confirmed by the single arc at all temperatures for $\mathrm{x}=0$, concentration with grain resistance $\left(\mathrm{R}_{\mathrm{g}}\right)$, grain capacitance $\left(\mathrm{C}_{\mathrm{g}}\right)$ evaluated from the plot is given in Table 2. When we add $\mathrm{CaSnO}_{3}$ and $\mathrm{CaSeO}_{3}$ to the parent compound (i.e., for $\mathrm{x}=0.05,0.10,0.15$ compositions) up to $300{ }^{\circ} \mathrm{C}$ 
temperature, all the curves are fitted with the (RQC) circuit elements, but for other high temperatures (i.e., for $350^{\circ} \mathrm{C}$ and $400^{\circ} \mathrm{C}$ ) the experimental values of the impedance are fitted by two semicircular arcs with the equivalent circuit elements (RQC)-(RC) joined in parallel.

By using the fitted curves of the impedance the grain resistance $\left(\mathrm{R}_{\mathrm{g}}\right)$, capacitance grain capacitance $\left(\mathrm{C}_{\mathrm{g}}\right)$, constant phase element $(\mathrm{CPE})$, grain boundary resistance $\left(\mathrm{R}_{\mathrm{gb}}\right)$, grain boundary capacitance $\left(\mathrm{C}_{\mathrm{gb}}\right)$ of these two high compositions are also compared in Table 2 . In the current situation, there is a very good agreement between the experimentally observed impedance data and the fitted data for all temperatures and all concentrations. For a better understanding of the relaxation behavior (whether Debye or non Debye type), the equivalent depressed semicircular curves for all the compositions corresponding to the temperature $300{ }^{\circ} \mathrm{C}$ have been drawn and shown by Figure 4(c). The depression angles at $300^{\circ} \mathrm{C}$ where only grain effect is observed are given by $\theta_{\mathrm{g}}$ is equal to $3.05^{\circ}, 2.39^{\circ}, 6.39^{\circ}$, and $10.8^{\circ}$ for $\mathrm{x}=0.05,0.10,0.15$ respectively. These depression angles determine the degree of deviation from Debye behavior and confirm the nonDebye type relaxation present in the studied materials.

Table 3: Comparison of resistance, capacitance, and constant phase elements of grain interior as well as grain boundary of BNT-CSn-CSe with different concentrations $(x=0,0.05,0.1,0.15)$ at various temperatures $\left(100^{\circ} \mathrm{C}-400^{\circ} \mathrm{C}\right)$.

\begin{tabular}{|c|c|c|c|c|c|c|c|}
\hline $\begin{array}{c}\text { Composition } \\
\text { of the } \\
\text { sample }\end{array}$ & $\begin{array}{c}\text { Temp. } \\
\left({ }^{\circ} \mathrm{C}\right)\end{array}$ & Model & $\mathrm{C}_{\mathrm{b}}(\mathrm{F})$ & $\mathrm{CPE}(\mathrm{Q})$ & $\mathrm{R}_{\mathrm{b}}(\Omega)$ & $\mathrm{C}_{\mathrm{gb}}(\mathrm{F})$ & $\mathrm{R}_{\mathrm{gb}}(\mathrm{F})$ \\
\hline $\mathrm{x}=0$ & 25 & $(\mathrm{RQC})$ & $2.90 \times 10^{-10}$ & $5.13 \times 10^{-08}$ & $9.46 \times 10^{6}$ & & \\
\hline & 50 & $(\mathrm{RQC})$ & $9.05 \times 10^{-10}$ & $3.45 \times 10^{-10}$ & $9.26 \times 10^{5}$ & & \\
\hline & 100 & $(\mathrm{RQC})$ & $6.07 \times 10^{-09}$ & $4.98 \times 10^{-10}$ & $8.81 \times 10^{5}$ & & \\
\hline & 150 & $(\mathrm{RQC})$ & $1.50 \times 10^{-08}$ & $5.88 \times 10^{-10}$ & $2.65 \times 10^{7}$ & & \\
\hline & 200 & $(\mathrm{RQC})$ & $2.11 \times 10^{-09}$ & $7.19 \times 10^{-10}$ & $6.10 \times 10^{7}$ & & \\
\hline & 250 & $(\mathrm{RQC})$ & $3.98 \times 10^{-08}$ & $8.00 \times 10^{-10}$ & $7.14 \times 10^{7}$ & & \\
\hline & 300 & $(\mathrm{RQC})$ & $7.26 \times 10^{-10}$ & $1.58 \times 10^{-09}$ & $7.28 \times 10^{7}$ & & \\
\hline & 350 & $(\mathrm{RQC})$ & $8.13 \times 10^{-10}$ & $2.34 \times 10^{-09}$ & $8.66 \times 10^{7}$ & & \\
\hline & 400 & $(\mathrm{RQC})$ & $6.80 \times 10^{-10}$ & $3.24 \times 10^{-09}$ & $1.19 \times 10^{8}$ & & \\
\hline $\mathrm{x}=0.05$ & 25 & $(\mathrm{RQC})$ & $1.55 \times 10^{-10}$ & $2.37 \times 10^{-10}$ & $1.47 \times 10^{7}$ & & \\
\hline & 50 & $(\mathrm{RQC})$ & $1.71 \times 10^{-10}$ & $3.06 \times 10^{-10}$ & $1.77 \times 10^{6}$ & & \\
\hline & 100 & $(\mathrm{RQC})$ & $1.92 \times 10^{-10}$ & $1.03 \times 10^{-09}$ & $1.10 \times 10^{6}$ & & \\
\hline
\end{tabular}




\begin{tabular}{|c|c|c|c|c|c|c|c|}
\hline & 150 & (RQC) & $1.82 \times 10^{-10}$ & $2.25 \times 10^{-10}$ & $2.03 \times 10^{6}$ & & \\
\hline & 200 & (RQC) & $1.68 \times 10^{-10}$ & $1.73 \times 10^{-10}$ & $4.36 \times 10^{6}$ & & \\
\hline & 250 & (RQC) & $1.42 \times 10^{-10}$ & $1.80 \times 10^{-10}$ & $5.39 \times 10^{6}$ & & \\
\hline & 300 & $\overline{(\mathrm{RQC})}$ & $4.64 \times 10^{-10}$ & $3.10 \times 10^{-10}$ & $6.39 \times 10^{6}$ & & \\
\hline & 350 & $\begin{array}{c}\text { RQC) } \\
(\mathrm{RC})\end{array}$ & $1.24 \times 10^{-10}$ & $2.37 \times 10^{-09}$ & $1.18 \times 10^{7}$ & $3.19 \times 10^{-10}$ & $1.74 \times 10^{6}$ \\
\hline & 400 & $\begin{array}{c}\text { (RQC) } \\
(\mathrm{RC})\end{array}$ & $1.23 \times 10^{-10}$ & $1.10 \times 10^{-09}$ & $8.47 \times 10^{7}$ & $4.19 \times 10^{-10}$ & $4.25 \times 10^{6}$ \\
\hline \multirow[t]{9}{*}{$\mathrm{x}=0.10$} & 25 & (RQC) & $2.67 \times 10^{-10}$ & $1.35 \times 10^{-08}$ & $3.30 \times 10^{6}$ & & \\
\hline & 50 & (RQC) & $2.95 \times 10^{-10}$ & $5.73 \times 10^{-09}$ & $1.22 \times 10^{6}$ & & \\
\hline & 100 & (RQC) & $2.88 \times 10^{-10}$ & $4.61 \times 10^{-10}$ & $1.05 \times 10^{7}$ & & \\
\hline & 150 & (RQC) & $2.83 \times 10^{-10}$ & $5.04 \times 10^{-10}$ & $1.47 \times 10^{6}$ & & \\
\hline & 200 & (RQC) & $2.74 \times 10^{-10}$ & $3.74 \times 10^{-10}$ & $1.20 \times 10^{7}$ & & \\
\hline & 250 & (RQC) & $2.80 \times 10^{-10}$ & $2.33 \times 10^{-09}$ & $2.69 \times 10^{7}$ & & \\
\hline & 300 & (RQC) & $2.77 \times 10^{-10}$ & $6.07 \times 10^{-09}$ & $4.69 \times 10^{7}$ & & \\
\hline & 350 & $\begin{array}{c}\text { (RQC) } \\
(\mathrm{RC})\end{array}$ & $2.69 \times 10^{-10}$ & $1.21 \times 10^{-08}$ & $5.76 \times 10^{7}$ & $8.04 \times 10^{-07}$ & $4.68 \times 10^{7}$ \\
\hline & 400 & $\begin{array}{c}\text { RQC) } \\
(\mathrm{RC})\end{array}$ & $2.66 \times 10^{-10}$ & $3.25 \times 10^{-08}$ & $9.15 \times 10^{7}$ & $2.30 \times 10^{-07}$ & $5.34 \times 10^{7}$ \\
\hline \multirow[t]{9}{*}{$\mathrm{x}=0.15$} & 25 & (RQC) & $2.36 \times 10^{-10}$ & $3.07 \times 10^{-09}$ & $1.31 \times 10^{5}$ & & \\
\hline & 50 & (RQC) & $2.65 \times 10^{-10}$ & $2.27 \times 10^{-09}$ & $1.15 \times 10^{6}$ & & \\
\hline & 100 & (RQC) & $2.60 \times 10^{-10}$ & $1.82 \times 10^{-09}$ & $1.18 \times 10^{6}$ & & \\
\hline & 150 & (RQC) & $2.56 \times 10^{-10}$ & $1.82 \times 10^{-09}$ & $1.19 \times 10^{6}$ & & \\
\hline & 200 & (RQC) & $2.56 \times 10^{-10}$ & $2.61 \times 10^{-09}$ & $4.53 \times 10^{7}$ & & \\
\hline & 250 & (RQC) & $2.54 \times 10^{-10}$ & $2.86 \times 10^{-09}$ & $4.86 \times 10^{6}$ & & \\
\hline & 300 & (RQC) & $2.54 \times 10^{-10}$ & $5.83 \times 10^{-09}$ & $1.15 \times 10^{7}$ & & \\
\hline & 350 & $\begin{array}{c}\text { (RQC) } \\
(\mathrm{RC})\end{array}$ & $2.26 \times 10^{-10}$ & $1.75 \times 10^{-09}$ & $3.49 \times 10^{7}$ & $2.07 \times 10^{-09}$ & $5.26 \times 10^{7}$ \\
\hline & 400 & $\begin{array}{c}\text { RQC) } \\
(\mathrm{RC})\end{array}$ & $2.38 \times 10^{-10}$ & $9.81 \times 10^{-09}$ & $4.11 \times 10^{7}$ & $2.50 \times 10^{-09}$ & $1.97 \times 10^{7}$ \\
\hline
\end{tabular}




\subsection{Conductivity study}

The study of ac conductivity is valuable for a better understanding of the electrical conductivity of the compound employing its frequency dependency. The variation of ac conductivity with frequency gives the information regarding the behavior of the charge carriers (electrons and holes). By using the dielectric parameters, the calculation of ac conductivity is carried out with an empirical formula,

$$
\sigma_{a c}=\omega \varepsilon_{0} \varepsilon_{r} \tan \delta
$$

Where $\sigma_{\mathrm{ac}}$ is the ac conductivity, $\omega$ is $2 \pi \mathrm{f}$ is the angular frequency, $\varepsilon_{0}$ is the permittivity of free space, $\varepsilon_{\mathrm{r}}$ is the dielectric constant (relative permittivity) and $\tan \delta$ is the dielectric loss. The detailed study of the ac conductivity of the material Jonscher's universal power law $[66,67]$ can be followed, which is given by

$$
\sigma_{T}(\omega)=\sigma(0)+\sigma_{1}(\omega)=\sigma_{0}+A \omega^{n}
$$

Where $\sigma_{\mathrm{T}}$ represents the total electrical conductivity, $\sigma(0)$ represents the frequency-dependent term which gives the dc conductivity, $\sigma_{1}(\omega)$ is the completely dispersive term of ac conductivity, $\mathrm{A}$ is the temperature dependence constant determines the polarizability strength whereas $\mathrm{n}$ is defined as the frequency exponent having the numerical value between 0 and 1 and this signifies the amount of interaction of the mobile charge carries with the surrounding lattices, it dependents on the nature of the material and temperature but independent of the frequency.

\subsubsection{Effect of frequency on ac conductivity study.}

The variation of ac conductivity with the frequency of the compounds BNT-CSn-CSe with different temperatures $\left(25{ }^{\circ} \mathrm{C}-400{ }^{\circ} \mathrm{C}\right)$ is shown in Figure 5(a). With raise in frequency, ac conductivity value also increases. This increasing tendency determines the disordering of the cations between the space charges and neighboring sites [68]. In the region of high frequency, all the ac conductivity curves come closer to one another, and combine to a particular slope, suggest that all the plots display the dispersion phenomenon at low frequency following Jonscher's

power law. According to Jonscher, the source of frequency-dependent ac conductivity lays in the relaxation phenomenon because of the movable charge carriers. When the hopping of charge carriers takes place from their original site to another new site, they remain in the state of motion between the two minima of the potential energy. Jonscher's power states that the relaxation is caused by the mobile charge carriers when transiting from the initial state of minimum potential energy to a new site, which is a state between two potential energy minima. In this figure, we 
also observed a plateau-like pattern in the low-frequency region at the high-temperature side for all the composition which proposes the frequency independence of ac conductivity, and provides the dc conductivity.
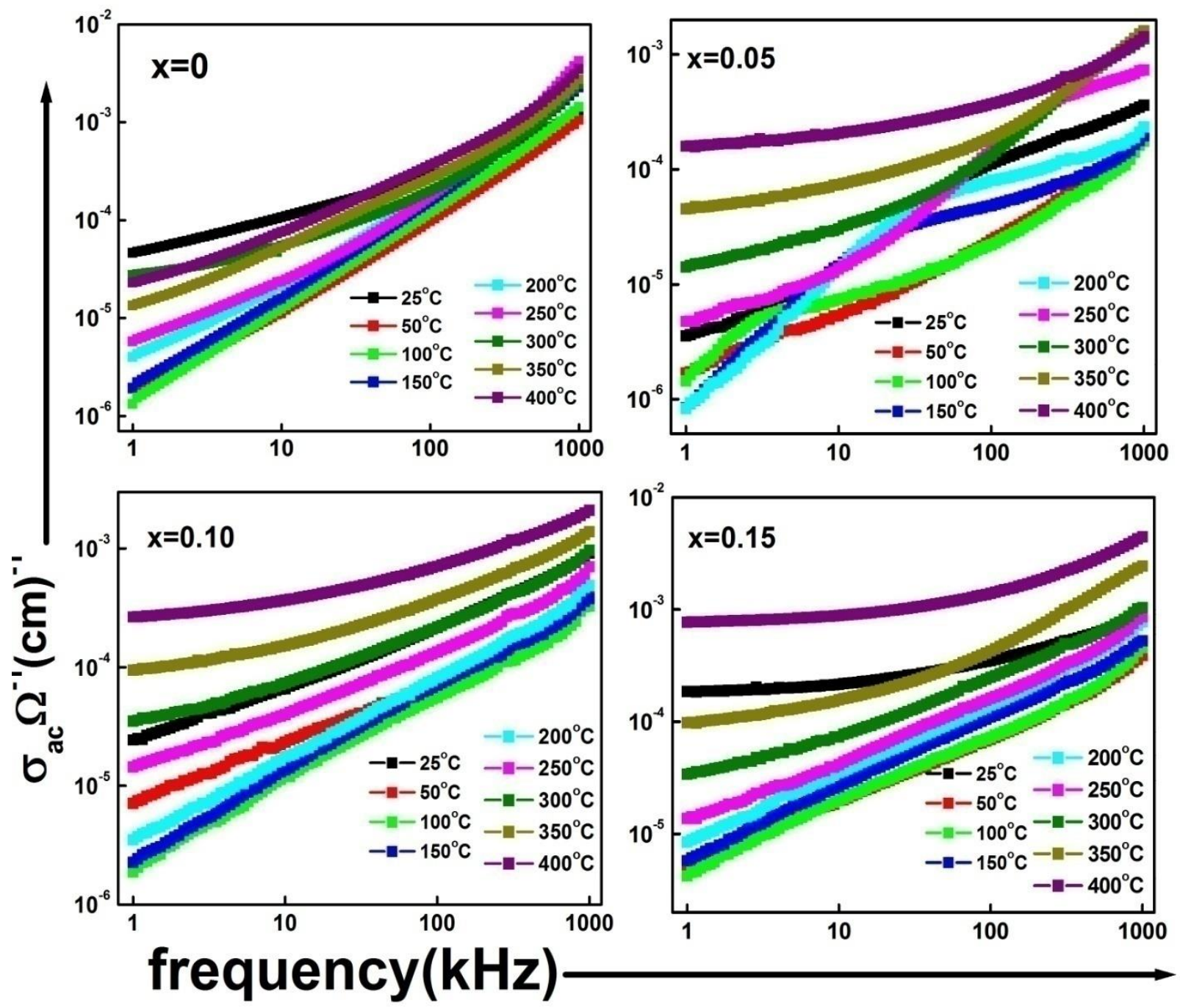

Figure 5(a): Frequency dependence of ac conductivity of (1-2x) BNT- x CSn - x CSe ceramics at different temperatures $\left(25^{\circ}-400^{\circ} \mathrm{C}\right)$ with $(\mathrm{x}=0,0.05,0.1,0.15)$.

In this region, the occurrence of the conduction mechanism is caused by the wide range of translational motion of the charge carrier, which happens because of the hopping of charge carriers from one local state to another, and gives rise to the frequency-independent $\sigma_{\mathrm{dc}}$ part [69].

\subsubsection{Effect of temperature on ac conductivity}

The variation of the logarithmic value of ac conductivity with the inverse of the absolute temperature of the studied compounds BNT-CSn-CSe at different concentrations $(x=0,0.05,0.1$, 
0.15) with a wide range of frequency is given in Figure 5(b). The calculation of ac conductivity is done by using the experimental formula given above.

The ac conductivity increases remarkably with the increase in frequency at the low frequencies suggesting the dispersion of conductivity with frequency but decreases with the decrease of temperature. The activation energy in the basis of thermally activated procedure is determined by using the Arrhenius equation [70],

$$
\sigma_{a c}=\sigma_{0} \exp \left(\frac{-E_{a}}{K_{B} T}\right)
$$

Where $\sigma_{0}$ is the pre-exponential factor also called conductivity at room temperature, $\mathrm{T}$ is the absolute temperature and $\mathrm{K}_{\mathrm{B}}$ is the Boltzmann constant. This energy is essential for converting the bound charge carrier into a movable one to participate in the conduction process and evaluated from the slope of the curves which are fitted linearly. The presence of different slopes at various temperatures for every frequency recommends the existence of multiple conduction mechanisms with a different value of activation energy [71]. 

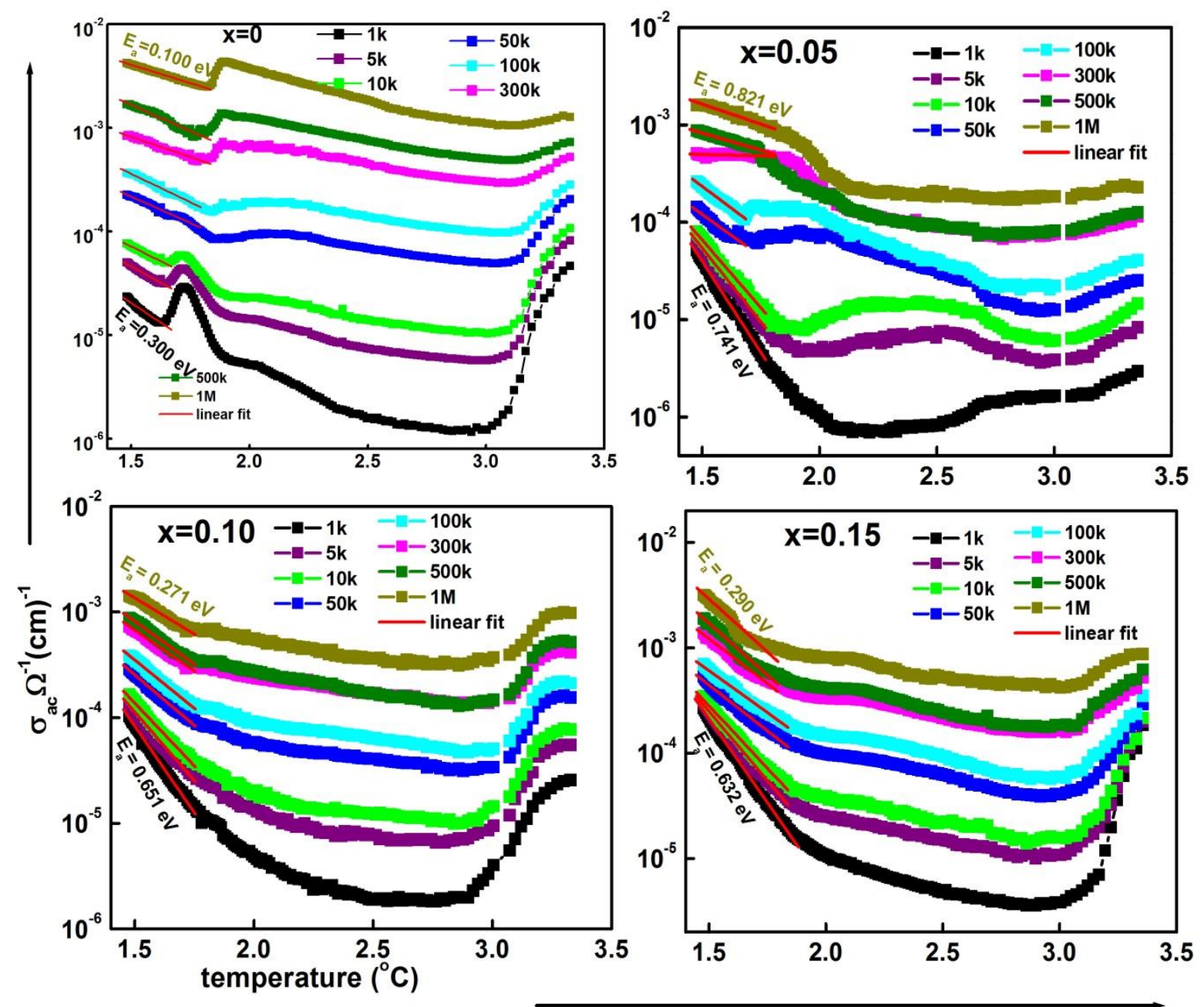

Figure 5(b): Variation of AC-conductivity with inverse temperature of (1-2x) BNT- x CSn $x$ CSe ceramics at different frequency $(1 \mathrm{kHz}-1 \mathrm{MHz})$ with $(\mathrm{x}=0,0.05,0.10,0.15)$.

In this figure, the different values of activation energy are calculated from the corresponding different values of the slope at high temperature describing a particular conduction mechanism for all frequencies. The different values of activation energy at different frequencies for all compositions are given in table 4. 
Table 4: Comparison of activation energy $\left(E_{a}\right)$ of (1-2x) BNT-x CSn-x CSe with (x=0, 0.05, $0.1,0.15)$ at different frequency $(1 \mathrm{kHz}-1 \mathrm{MHz})$.

\begin{tabular}{|c|c|c|c|c|c|c|c|c|}
\hline \multicolumn{7}{|c|}{ Activation energy $\left(\mathrm{E}_{\mathrm{a}}\right)(\mathrm{eV})$} \\
\hline $\begin{array}{c}\text { Composition } \\
(\mathrm{x})\end{array}$ & \multicolumn{7}{|c|}{ Frequency $(\mathrm{kHz})$} \\
\cline { 2 - 10 } & 1 & 5 & 10 & 50 & 100 & 300 & 500 & 1000 \\
\hline 0.00 & 0.3004 & 0.2501 & 0.2254 & 0.2025 & 0.2018 & 0.1548 & 0.1218 & 0.1005 \\
\hline 0.05 & 0.7414 & 0.6031 & 0.5532 & 0.3433 & 0.2094 & 0.2011 & 0.1939 & 0.1630 \\
\hline 0.10 & 0.6515 & 0.5162 & 0.4718 & 0.3805 & 0.3639 & 0.3484 & 0.3228 & 0.2711 \\
\hline 0.15 & 0.6324 & 0.5203 & 0.4709 & 0.3454 & 0.3162 & 0.3076 & 0.2922 & 0.2905 \\
\hline
\end{tabular}

It is noticed that with the rise in frequency the values of activation energy reduces. The conductivity raises with rise in temperature indicates the presence of NTCR behavior in the material. At high temperatures, more amount of energy is required to overcome the thermal fluctuation occurring due to charge carriers. This is because, at the low frequencies, the conductivity is taken by mobility or transportation over long distances rather than by relaxation/orientation mechanism. The energy required for the relaxation/orientation process is greater than that required for the mobility of charge carriers over longer distances [72,73]. The greater value of ac conductivity at higher temperature demonstrates the major character of ionic charge carriers like oxygen vacancy during the sintering process given by the following equation, $\mathrm{O}_{0} \rightarrow \frac{1}{2} \mathrm{O}_{2} \uparrow+V_{0}^{\bullet \bullet}+2 e^{-}$

Where $V_{0}^{\bullet \bullet}$ indicates the oxygen vacancy, and this increases the conductivity, gathering of space charge in the boundary area and also the loss factor $[74,75]$. 


\subsection{Modulus study}

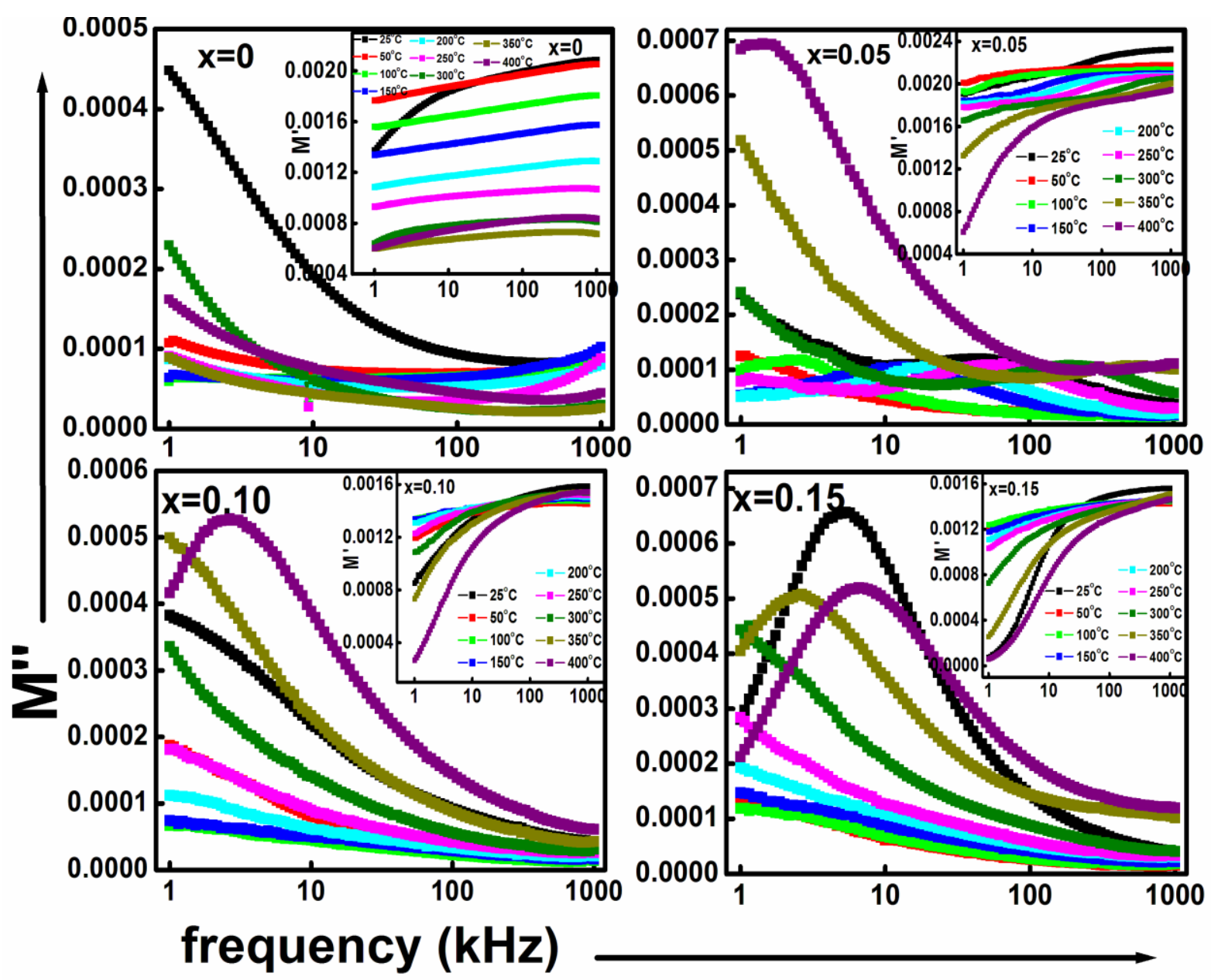

Figure 6: Frequency dependence of $M^{\prime}$ and $M^{\prime \prime}(1-2 x)$ BNT- $x$ CSn $-x$ CSe ceramics at different temperature $\left(25^{\circ} \mathrm{C}-400^{\circ} \mathrm{C}\right)$ with $(\mathrm{x}=0,0.05,0.10,0.15)$.

To detect electrode polarization, electrical conductivity, grain, and grain boundary conduction effect as well as relaxation phenomena of the synthesized material, the analysis of complex modulus is essentially required. These parameters provide information regarding electrical processes taking place in the compounds at various frequencies and temperatures. Dielectric relaxation suggests various microscopic polarization processes occurring in the compounds by the application of an external electric field. In other words, dielectric relaxation is directly connected with the decay rate of the polarization processes. In this technique, the electrode 
polarization gets suppressed whereas capacitance value gets dominated. Complex electrical modulus $\left(M^{*}\right)$ can be defined by the following relations [76],

$$
\begin{aligned}
& M^{*}=M^{\prime}+j M^{\prime \prime}=j \omega C_{0} Z=\frac{1}{\varepsilon *}, \text { Where } \\
& M^{\prime}=B\left[\frac{(\omega R C)^{2}}{1+(\omega R C)^{2}}\right]=B\left[\frac{\omega^{2} \tau^{2}}{1+\omega^{2} \tau^{2}}\right] \text { or } \omega C_{0} Z^{\prime \prime}
\end{aligned}
$$

And

$$
M^{\prime \prime}=B\left[\frac{\omega R C}{1+(\omega R C)^{2}}\right]=B\left[\frac{\omega \tau}{1+\omega^{2} \tau^{2}}\right] \text { or } \omega C_{0} Z^{\prime}
$$

In the above relations $\varepsilon^{*}$ is the complex dielectric permittivity, $\tau=\mathrm{RC}$ is the relaxation time, $\omega=2 \pi \mathrm{f}$ is the angular frequency, and $\mathrm{B}=\mathrm{C}_{0} / \mathrm{C}$, where $\mathrm{C}$ is the measured capacitance.

Figure 6 (insert) depicts the frequency dependence of real part of modulus (M') of the synthesized samples, BNTC-CSn-CSe for all compositions (with $\mathrm{x}=0,0.05,0.10,0.15$ ) at different temperatures $\left(25^{\circ} \mathrm{C}-400{ }^{\circ} \mathrm{C}\right)$. For each composition, all-temperature curves indicate that the value of $\mathrm{M}^{\prime}$ increases with an increase in frequency. These curves (except the parent compound) combine and attend the maximum value $\left(\mathrm{M}_{\text {max }}^{\prime}\right)$ at high frequency. In the lowfrequency region, the value of $\mathrm{M}^{\prime}$ is approaching zero. The smallest values of $\mathrm{M}^{\prime}$ indicate the less or absence of electrode and ionic polarization in that range of temperature. This also maybe because of the presence of conduction phenomenon as well as short-range mobility of charge carriers. The mobility of charge carriers is controlled by the electric field in the absence of restoring force and the short-range mobility of charge carriers primarily responsible for the conduction process [77]. Figure 6 represents the frequency dependence of the imaginary part of the complex modulus $\left(\mathrm{M}^{\prime \prime}\right)$ of the studied compounds at different temperatures $\left(25^{\circ} \mathrm{C}-400{ }^{\circ} \mathrm{C}\right)$. It is apparent from the graph that $\mathbf{M}^{\prime \prime}$ attends a maximum value for all compositions at a particular frequency called relaxation frequency. Imaginary modulus peaks are experientially observed in the range of frequencies where ions/ charge carriers move a long distance. In the region of high frequency, the ions are confined to their potential wells and move locally. This peak shifts towards the higher frequency region with an increase in temperature. This nature of dielectric relaxation suggests that the hopping mechanism of charge carriers dominates intrinsically at higher temperatures in a thermally activated process. The asymmetric broadening of the peak 
depends on temperature; hence the relaxation process of the dissimilar time constant is achieved in the compound. This suggests the non Debye type of relaxation in the materials [78].

\subsection{JE characteristics}

The room temperature J-E characteristics (leakage current characteristics) of the synthesized material, BNTC-CSn-CSe for all compositions (with $\mathrm{x}=0,0.05,0.10,0.15$ ) are studied from I-V data as shown in Figure 7(a). These J-E curves are taken in both negative and positive bias (with E varies from $-100 \mathrm{kV} / \mathrm{cm}$ to $100 \mathrm{kV} / \mathrm{cm}$ through 0 ), and are very symmetric on both sides which confirms the Ohmic nature. Out of $100 \mathrm{kV} / \mathrm{cm}$ of the electric field value up to $1 \mathrm{kV} / \mathrm{cm}$, the leakage current density (J) increases very sharply for both sides and all compositions. Similarly, up to $50 \mathrm{kV} / \mathrm{cm}$, the $\mathrm{J}$ value rises slowly and has a saturation value, and after that, the $\mathrm{J}$ value becomes almost constant. From this graph, it is clear that with the addition of CSn-CSe in equal percentage, the $\mathrm{J}$ values decreases effectively and are found to be $3.98 \times 10^{-5}, 1.02 \times 10^{-5}, 2.0 \times 10^{-6}$ and $1.52 \times 10^{-7} \mathrm{~A} / \mathrm{cm}^{2}$ for $\mathrm{x}=0,0.05,0.10$ and 0.15 respectively. These values suggest that for $\mathrm{X}=0.15$, the attained $\mathrm{J}$ values are of two order less than that of pure BNT compound suggesting very good application for device fabrication [79, 80]. The J-E characteristics, plotted in logarithm scale for all compositions, are shown in Figure 7(b). In the low-field region, the leakage current density $(\mathrm{J})$ possesses a small value, and with an increase in an applied electric field, the $\mathrm{J}$ value raises suddenly, which proposes various conduction mechanisms governing the conduction process. This applied voltage (E) dependence current density $(\mathrm{J})$ plot follows a powerlaw behavior with two different slopes in two voltage regions is given by $\mathrm{J} \propto \mathrm{E}^{\mathrm{n}}$ i.e,

$$
n=\frac{d(\log J)}{d(\log E)}
$$

Where $\mathrm{n}$ is the power index or slope of $\log \mathrm{J} \sim \log \mathrm{E}$ plot and have the different values in both low and high voltage regions. In lower voltage region $\mathrm{n}=1$ (i.e., $\mathrm{J} \propto \mathrm{E}$ ) known as the ohmic region and in higher voltage region $\mathrm{n}=2$ (i.e., $\mathrm{J} \propto \mathrm{E}^{2}$ ) known as space charge limited conduction (SCLC) region or trapped charge limited region. 

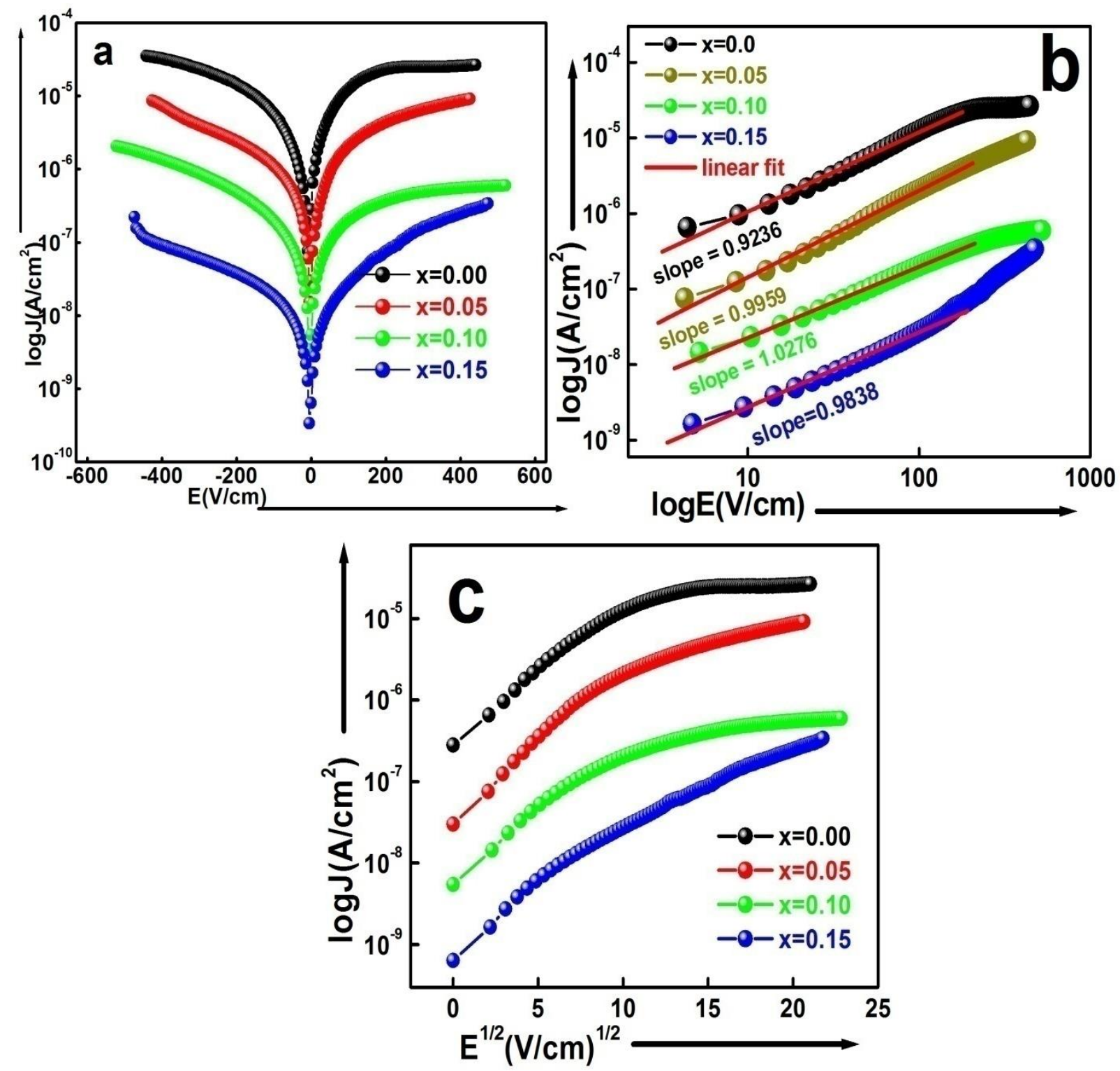

Figure 7 (a) $\log J$ versus $E$ plot (b) $\log J$ versus $\log E$ plot, (c) $\log J$ versus $E^{1 / 2}$ plot of (1-2x) BNT-x CSn - x CSe at room temperature for different concentrations $(x=0,0.05,0.1$ and 0.15).

Here, in this case, the only first region is taken where $\log \mathrm{J}$ varies directly with $\log$ E suggesting the presence of Ohmic conduction in studied compounds. In the region of the high electric field, the values of the slope are found to be $\approx 2$ indicating SCLC is absent, hence only at lower voltage region is considered for application [81]. The Ohmic, as well as SCLC conduction mechanisms can also be described by the following relation,

$J=q \mu n_{0} E$ 
Where $\mathrm{q}$ is the standard electric charge, $\mu$ is the transport band electron mobility; $\mathrm{n}_{0}$ is the charge carriers which are thermally generated and $\mathrm{E}$ is the applied electric field [82]. The ohmic nature in the lower field region is due to the existence of an excess amount of thermally generated charge carriers. For further investigation of the JE characteristics, another conduction mechanism has been considered known as Schottky emission (SE) (log J versus $E^{1 / 2}$ ) shown in figure 7(c). Depending upon the nature of charge transportation, the experimentally observed data should satisfy linear fit, whereas the theoretical magnitude of slopes should determine the optical dielectric constant of samples. This straight-line fitting specifies that the creation of a Schottky type barrier between the electrode and insulating layer causes difficulty for the electrons to cross it, hence results the minimal conduction.

The Schottky-Richardson current-voltage relation is given by

$$
\begin{aligned}
& \log J_{s}=\log A T^{2}-\frac{\phi_{b}}{k_{B} T}+\beta_{s} E^{1 / 2} \\
& \text { And } \beta_{s}=\frac{1}{k_{B} T}\left(\frac{q^{3}}{4 \pi \varepsilon_{r} \varepsilon_{0}}\right)^{\frac{1}{2}}
\end{aligned}
$$

Where $J_{\mathrm{s}}$ is the current density across the Schottky type barrier, $\mathrm{A}$ is a constant known as Richardson constant, $\mathrm{k}_{\mathrm{B}}$ is the Boltzmann constant, $\mathrm{T}$ is the absolute temperature, $\varphi_{\mathrm{b}}$ is the height of Schottky barrier (voltage across the barrier) and $\mathrm{E}$ is the electric field [83-85]. The above relations specify that $\log \mathrm{J}_{\mathrm{s}}$ varies directly with $\mathrm{E}^{1 / 2}$. Here in the studied materials, for all compositions, the $\log \mathrm{J}$ versus $\mathrm{E}^{1 / 2}$ plots is nonlinear which suggests that the $\mathrm{SE}$ mechanism is absent. 


\subsection{Polarization Study}

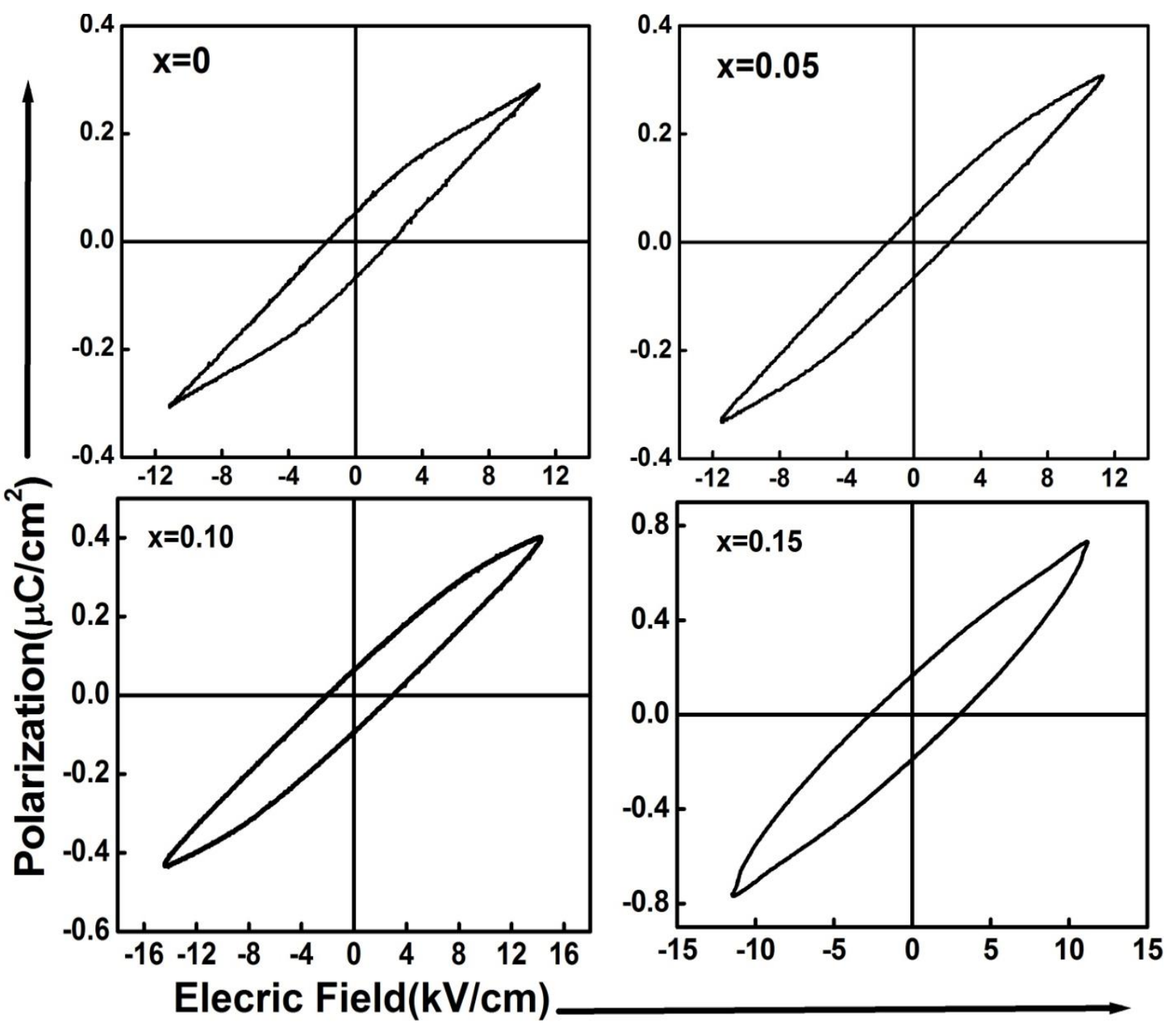

Figure 8: P-E hysteresis loop of (1-2x) BNT-x CSn-x CSe ceramics with different concentration $(x=0,0.05,0.1,0.15)$ at room temperature.

Ferroelectric behavior of the synthesized compound BNT-CSn-CSe at different concentrations $(\mathrm{x}=0,0.05,0.1,0.15)$ is confirmed from the room temperature polarization study as shown in Figure 8. In the case of normal dielectric material, a linear relation is found between electrical polarizations (P) and applied electric field (E), in other words, we can say that $\mathrm{P}$ varies directly with E. However, for ferroelectric materials, instead of the linear relation, a hysteresis loop is established, and this is the significant characteristic of such type of materials. In the present study, the ferroelectric loops for all compositions were taken at room temperature $\left(25{ }^{\circ} \mathrm{C}\right)$ at a constant frequency $(50 \mathrm{~Hz})$ and applied field of $12 \mathrm{kV} / \mathrm{cm}$ on the different thickness of samples 
$2.34 \mathrm{~mm}, 2.23 \mathrm{~mm}, 1.91 \mathrm{~mm}$ and $2.11 \mathrm{~mm}$ for $\mathrm{x}=0,0.05,0.10,0.15$ respectively. It is notice in the graphs that the applied field is not sufficient to give a saturated P-E loop due to experimental limitation. On the other hand, the observed loop also confirms the existence of the ferroelectric behavior of the studied materials. The unsaturated hysteresis loop is also due to the leakage current of the sample. The area under the loop determines the dissipation of the energy of the sample. According to the review of literature, at room temperature, the remnant polarization $\left(\mathrm{P}_{\mathrm{r}}\right)$ and the coercive field $\left(\mathrm{E}_{\mathrm{c}}\right)$ of the pure $\mathrm{Bi}_{0.5} \mathrm{Na}_{0.5} \mathrm{TiO}_{3}(\mathrm{BNT})$ compound are found to be $38 \mu \mathrm{C} / \mathrm{cm}$ and $73 \mathrm{kV} / \mathrm{cm}$ respectively [86]. The coercive field is the field where the remnant polarization becomes zero. Here, the $2 \mathrm{P}_{\mathrm{r}}$ and $\mathrm{E}_{\mathrm{c}}$ of the compounds is found to be (0.128 and 2.393), (0.119 and 2.661), (0.166 and 2.371), (0.369 and 3.111) for $\mathrm{x}=0,0.05,0.1,0.15$ respectively. This result shows with an increase in the concentrations the value of $2 \mathrm{P}_{\mathrm{r}}$ and $\mathrm{E}_{\mathrm{c}}$ increases.

\section{Summary and Conclusion}

The polycrystalline samples of BNT-CSn-CSe with different concentrations $x=(0,0.05,0.10$, 0.15) were successfully synthesized using a standard high-temperature solid-state reaction technique. The calcination and sintering temperature were optimized at $925^{\circ} \mathrm{C}$ and $950{ }^{\circ} \mathrm{C}$ respectively by a repeated firing method. Structural as well as different electrical behaviors (dielectric, impedance, conductivity, modulus) of the parent BNT compound and with the substitution of an equal percentage of $\mathrm{CaSnO}_{3}$ and $\mathrm{CaSeO}_{3}$ (i.e., for $\mathrm{x}=0.05,0.10,0.15$ ) are studied as a function of both frequency and temperature. Preliminary structure study is performed by room temperature XRD pattern indicating the samples exhibit rhombohedral phase with the non-Centro symmetry space group R3c, achieved from JCPDS diffraction pattern. For better information regarding structural analysis, Rietveld refinement was carried out by using Maud software. The frequency dependence of dielectric constant (relative permittivity) obeys the Maxwell- Wagner theory based on Koop's bi-layers model, and also gives information regarding types of polarization mechanism, while the dielectric loss explains the dipole relaxation behaviors. The compounds possess a high dielectric constant and low tangent loss at room temperature, making them attractive for device applications. The maximum value of dielectric constant and loss tangent of the pure BNT compound at $1 \mathrm{kHz}$ was found to be 1653 and 0.27 respectively. In the temperature dependence of dielectric curves, two anomalies first observed around $210{ }^{\circ} \mathrm{C}$ responsible for the phase transition from ferroelectric to anti-ferroelectric, and the second one is observed around $320{ }^{\circ} \mathrm{C}$ signifies the anti-ferroelectric to the paraelectric phase 
transition. The impedance spectroscopy reveals that the material shows NTCR (semiconductor) behavior in the low-temperature region $\left(25-100{ }^{\circ} \mathrm{C}\right.$ ) and PTCR (positive temperature coefficient of resistance) is found in the high-temperature region i.e., $\left(150-400{ }^{\circ} \mathrm{C}\right)$. In the Nyquist plots, all the impedance curves are fitted by the equivalent circuit elements to determine the presence of grain and grain boundary effects. The parent compound (BNT) shows only grain effect whereas the other higher composition shows grain effect up to $300{ }^{\circ} \mathrm{C}$ and both grain and grain boundary effect from $350-400{ }^{\circ} \mathrm{C}$. The grain and grain boundary resistances, as well as capacitances, had shown in Table 3 gives complete information about NTCR and PTCR behaviors. The depressed semicircular arcs at $300{ }^{\circ} \mathrm{C}$ with depression angles $\left(\theta_{\mathrm{g}}\right)$ are equal to $3.05^{\circ}, 2.39^{\circ}, 6.39^{\circ}$, and $10.8^{\circ}$ for $\mathrm{x}=0.05,0.10,0.15$ respectively confirming the non Debye type relaxation behavior of the material. The frequency dependence of the ac conductivity obeys Jonscher's power law. In the temperature dependence ac conductivity, the activation energy $\left(E_{a}\right)$ is calculated from the Arrhenius equation and the separate values of slopes at the different temperature, proposes the multiple conduction mechanism with different $E_{a}$. The modulus spectrum helps to understand the transport phenomenon and the existence of the dielectric relaxation mechanism in the studied compound. J-E characteristics suggest the Ohmic nature (slope nearly equal to one) of the compound and Schottky emission is absent in the material. The nature of the P-E hysteresis loop confirms the existence of the ferroelectric behavior of the synthesized compounds. Consequently, the above electrical characteristics of the material suggest that the material can be used as electronic appliances for multifunctional applications.

Reference

[1] D. Damjanovic, Curr Opin Solid State Mater Sci. 3, 469-473 (1998)

[2] S. Zhang, R. Xia, T. R. Shrout, J Electroceramics 19, 251-257 (2007)

[3] R. C. Andrades, A. H.M Junior, L. F de Miranda, R.A Rocha, Mater. Sci. Forum 912, 97-101 (2018)

[4] Q. Li, L. Ning, B. Hu, H. Peng, N. Zhao, H. Fan, ceramics Int. 45, 1676-1682 (2019)

[5] Y. Saito, H. Takao, T. Tani, T. Nonoyama, K. Takatori, T. Homma, Nature 432, 84-87 (2004)

[6] Y. Wu, J. Chen, J. Yuan, J. Xing, Z. Tan, L. Jiang, J. Appl. Phys. 120, 194103 (2016)

[7] J. Rödel, W. Jo, K. T. Seifert, E. M. Anton,T. Granzow, D. Damjanovic, J. Am. Ceram. Soc. 92, 1153-1177 (2009) 
[8] T. Takenaka, H. Nagata and Y. Hiruma, Jpn. J. Appl. Phys. 47, 3787-3801 (2008)

[9] Yuka Takagi, Hajime Nagata, Tadashi Takenaka,J. Asian Ceram. Soc. 8, 1-7 (2020)

[10] J. A. Hermann-Muñoz, J.A. Rincón-López, D.A. Fernández-Benavides, R. Detsch, J.M. Alvarado-Orozco,A.R Boccaccini, J. Muñoz-Saldaña,Mater. Lett. 275, 128078 (2020)

[11] D. Lin, D. Xiao, J. Zhu, P. Yu, H. Yan, L. Li, Mater. Lett. 58, 615- 618 (2004)

[12] T. Takenaka, K. Maruyama, K. Sakata, Jpn. J. Appl. Phys. 30, 2236-2239 (1991)

[13] D. A. Fernandez-Benavides, A. I. Gutierrez-Perez, A. M. Benitez-Castro, M. T. AyalaAyala, B. Moreno-Murguia, J. Muñoz-Saldaña, Materials 11, 361 (2018)

[14] H. Lian, R. Cheng, Y. Qiu, J. Shi, X. Chen, J. Mater. Sci.: Mater. Electron (2020) https://doi.org/10.1007/s10854-020-03331-9

[15] J. Yin, C. Zhao, Y. Zhang, J. Wu, J. Am. Ceram. Soc.100, 5601-5609 (2017)

[16] S. Zinatloo-Ajabshir, M. Baladi, M. Salavati-Niasari, Ultrason Sonochem 72, 105420 (2021)

[17] S. Zinatloo-Ajabshir, M. Baladi, O. Amiri, M. Salavati-Niasari, Sep. Purif. Technol. 248, $117062(2020)$

[18]S. Zinatloo-Ajabshir, M. S. Morassaei, O. Amiri, M. Salavati-Niasari, Ceram. Int. 46, 6095$6107(2020)$

[19]Sahar Zinatloo-Ajabshir, M. S. Morassaei, O. Amiri, M. Salavati-Niasari, L. K. Foong,Ceram. Int. 46 17186-17196 (2020)

[20] S. A. Heidari-Asil, S. Zinatloo-Ajabshir, O. Amiri, M. Salavati-Niasari, Int. J. Hydrog. Energy 45, $22761-22774$ (2020)

[21] S. Zinatloo-Ajabshir, Z. Salehi, O. Amiri, M. Salavati-Niasari, Int. J. Hydrog. Energy 44, 20110-20120 (2019)

[22]M. S. Morassaei, S. Zinatloo-Ajabshir, M. Salavati-Niasari,Adv Powder Technol. 28, 697705 (2017)

[23]S. Zinatloo-Ajabshir, M. S. Morassaei, O. Amiri, M. Salavati-Niasari, L. K. Foong,Ceram. Int. 46, 17186-17196 (2020)

[24]S. Moshtaghi, S. Zinatloo-Ajabshir, M. Salavati-Niasari,J Mater Sci: Mater Electron 27, 425435 (2016)

[25]S. Zinatloo-Ajabshir, Z. Salehi, M. Salavati-Niasari,J. Clean. Prod 192, 678-687 (2018) 
[26]S. Zinatloo-Ajabshir, Z. Salehi, O. Amiri, M. Salavati-Niasari,J. Alloys Compd. 791, 792799 (2019)

[27] X. Y. Chen, C. M. Shi Ping Bao, H. Y. Zhang, J. Alloys Compd.497, 354-359 (2010)

[28] B. Lei, B. Li, H. Zhang, W. Li, Opt. Mater. 29, 1491-1494 (2007)

[29] S. Shojaei, S.A. Hassanzadeh-Tabrizi, M.Ghashang, Ceram. Int. 40, 9609-9613(2014)

[30] Z. Lu, J. Liu, Y.Tang, Y. Li, Inorg. Chem. Commun 7, 731-733 (2004)

[31] J. M. Henriques, E.W.S. Caetano, V. N. Freire, J. A. P. da Costa, E. L. Albuquerque, J. Phys.: Condens. Matter 19, 106214 (2007)

[32] H. Mizoguchi, P. M. Woodward, Chem. Mater. 16, 5233-5248 (2004)

[33] M. Ebert, D.Havlíček, Collect. Czech. Chem. Commun. 46, 1740-1747(1981)

[34] L. T. Vlaev, M. M. Nikolova, G. G. Gospodinov, Monatsh Chem. 136, 1553-1566 (2005)

[35] M.Wildner, G.Giester, N. Jb. Miner. Abh. 184, 29-37(2007)

[36]B. Deb, A. Ghosh, J. Appl. Phys 112, 024102 (2012)

[37] Q. Chen, K. Su, Z. Zhao, Q. Ma, J non-cryst solids. J Non-Cryst Solids 498, 448-454 (2018)

[38] G. E. Engel, S.Wilke, O. KoÈnig, K. D. M. Harris, F. J. J. Leusen, J. Appl. Cryst. 32, 11691179 (1999)

[39] G.Will, Powder Diffraction, (Springer-Verlag, Berlin, Heidelberg, 2006), pp. 44-69.

[40] H. G. Scott, J. Appl. Cryst. 16, 159-163 (1983)

[41] A. L. Patterson, Phys. Rev. 56, 978-982 (1939)

[42] P. Scherrer, Math.-Phys. Kl 2, 98-100 (1918)

[43] B. K.Bammannavar, L. R. Naik, Smart Mater. Struct. 18, 085013 (2009)

[44] C. G. Koops, Phys. Rev. 83,121-124 (1951)

[45] A. Hilczer, K. Kowalska, E. Markiewicz, A. Pietraszkob, B. Andrzejewski, Mater Sci Eng B 207, 47-55 (2016)

[46] S. Das, A.K. Biswal, K. Parida, R. N. P Choudhary, and A. Roy, Appl. Surf. Sci. 428, 356363 (2018)

[47] R. Das, R.N.P. Choudhary, Solid State Sci. 87, 1-8 (2019)

[48] M. Kumar, K.L. Yadav, J. Phys. Condens. Matter 19, 242202 (2007)

[49] M. Kumar, K.L. Yadav, G.D. Varma, Mater. Lett. 62, 1159-1161 (2008)

[50] Y.Lia, W. Chena, J.Zhoua, Q.Xua, H.Suna, M.Liao, Ceram Int. 31, 139-142 (2005) 
[51] B. Chu, D. Chen, G. Li, Q. Yin, J. Eur. Ceram. Soc 22, 2115-2121(2002)

[52] S.said, J.P.Mercurio, J. Eur. Ceram. Soc. 21, 1333-1336 (2001)

[53]X. Jian-Xiu, Z. Liang, Z. Cheng-Ju, Chin. Phys. Lett. 25, 4414-4416 (2001)

[54] T. Acharya, R.N.P. Choudhary, Appl. Phys. A 121, 707-714 (2015)

[55] N. Pradhani, P.K. Mahapatra, R.N.P. Choudhary, Ceram Int. 46, 4126-4136 (2020)

[56] P. Thongbai, S. Tangwancharoen, T. Yamwong, S. Maensiri, J. Phys.: Condens. Matter 20, 395227 (2008)

[57] A. G. Monteduro, Z. Ameer, M. Martino, A. P. Caricato, V. Tasco, I. C. Lekshmi, R. Rinaldi, A. Hazarika, D. Choudhury, D. D. Sarma, G. Maruccio, J. Mater. Chem. C 4, 10801087 (2016)

[58] M. Idrees, M. Nadeem, M.M. Hassan, J. Phys. D Appl. Phys. 43, 155401(2010)

[59] Z. Imran, M.A. Rafiq, M.M. Hasan, AIP Adv. 4, 067137(2014)

[60] A.R. James, C. Prakash, G. Prasad, J. Phys. D 39, 1635-1641 (2006)

[61] D.C. Sinclair, A.R. West, J. Appl. Phys. 66, 3850-3856 (1989)

[62] K. Parida, S.K. Dehury, R.N.P. Choudhary, J. Mater. Sci. Mater. Electron. 27, 11211-11219 (2016)

[63] B. Garbarz-Glos, W. Bąk, M. Antonova, M. Pawlik, Mater. Sci. Eng. 49, 012031(2013)

[64] O. Raymonda, R. Font, N. Su'arez-Almodovar, J. Portelles, J.M. Siqueiros, J. Appl. Phys. 97, 084108 (2005)

[65] M. A. Ahmed, S. F. Mansour, M. A. Abdo, Phys. Scr. 86, 025705 (2012)

[66]A.K. Jonscher, Nature. 267, 673-679 (1977)

[67]D.C. Sinclair, A.R. West, J. Appl. Phys. 66, 3850-3856 (1989)

[68] M. Pollak, T. H. Geballe, Phys. Rev.122, 1742-1753(1961)

[69] L. Agrawal, B. P. Singh, T. P. Sinha, Mat. Res. Bull. 44, 1858-1862 (2009)

[70] S.Halder, K. Parida, S. N. Das, S. K. Pradhan, S .Bhuyan, R.N.P. Choudhary, Phys. Lett. A 382, 716-722 (2018)

[71] R.N.P. Choudhary, D.K. Pradhan, C.M. Tirado, G.E. Bonilla, R.S. Katiyar, J. Mater. Sci. 42, 7423-7432 (2007)

[72]M. A. E. F. Gabal, Y.M. Al Angari, A.Y. Obaid, C R Chim 16, 704-711(2013)

[73]N. Hirose, A.R. West, J.Am. Ceram. Soc. 79, 1633(1996)

[74] J. Suchanicz, Mater. Sci. Eng. B 55,114-118 (1998) 
[75] S. Sen, R.N.P. Choudhary, Mater. Chem. Phys. 87, 256-263 (2004)

[76] R. Das, R. N. P. Choudhary, Applied Physics A 125, 864 (2019)

[77] I. M. Hodge, M. D. Ingram, A.R. West, J. Electroanal. Chem. 58, 429- 432 (1975)

[78] J. Liu, C. G. Duan, W. G. Yin, W. N. Mei, R. W. Smith, J. R. Hardy, J. Chem. Phys. 119, 2812-2819 (2003)

[79] A.Ghani, S.Yang, S.S Rajput, S. Ahmed, A.Murtaza, C. Zhou, Z. Yu, Y.Zhang, X. Song and X.Ren, J. Phys. D 51, 225002 (2018)

[80] S. Sharma, M. P. Cruz, J. M. Siqueiros, O. Raymond-Herrera,V. E. Alvarez, R. K. Dwivedi, J Mater Sci-Mater El. 30, 7447-7459 (2019)

[81] M. Bouzitoun, C. Dridi, R. Mlika, R. B. Chaabane, H. B.Ouada, N. Jabballah, H. Gam, M. Majdoub, Sens. Actuators B Chem. 126, 91-96 (2007)

[82] A. K. Jena, S. Satapathy, J. Mohanty, Phys. Chem. Chem. Phys. 21, 15854-15860 (2019) [83] M.A. Khan,T. P. Comyn, A.J. Bell, Appl. Phys. Lett. 92, 072908 (2008)

[84] M. M. Kamal, A. H. Bhuiyan, J. Mod. Mech. Eng. Technol. 2, 1-9 (2014)

[85] K. C. Verma, R. K. Kotnala, V.Verma, N.S. Negi, Thin Solid Films 518, 3320-3325 (2010)

[86] R. Muanghlua, S. Niemcharoen, W. C. Vittayakorn, N. Tungsitvisetkul, P.Chinwaro, A. Ruangphanit, N. Chaiyo, N. Vittayakorn, Ferroelectrics 383, 1-7 (2009) 


\section{Figures}

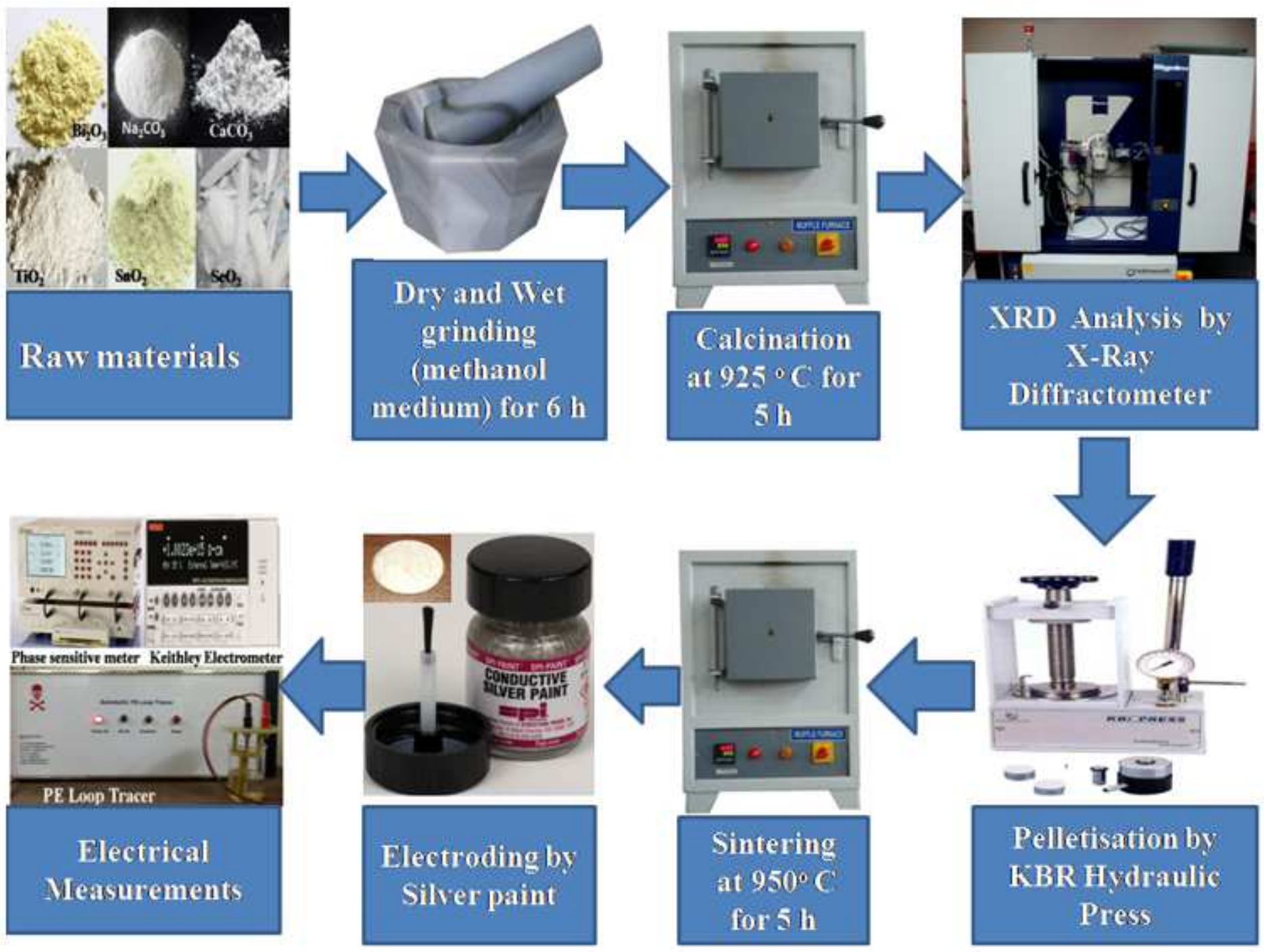

\section{Figure 1}

Schematic diagram of synthesis through solid-state reaction method and characterization of (1-2x) BNT$x$ CSn- x CSe compounds with different percentage $(x=0,0.05,0.1,0.15)$. 


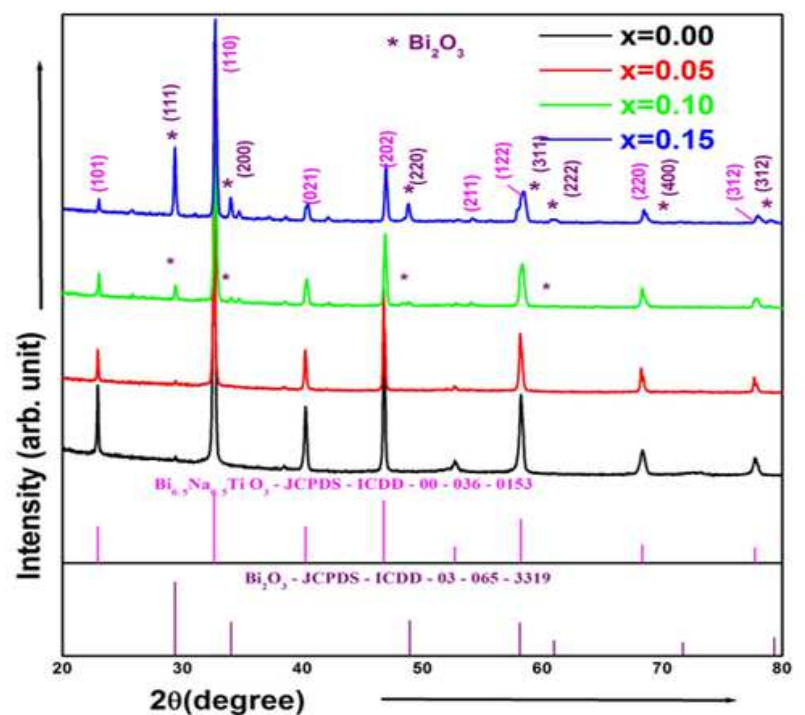

a
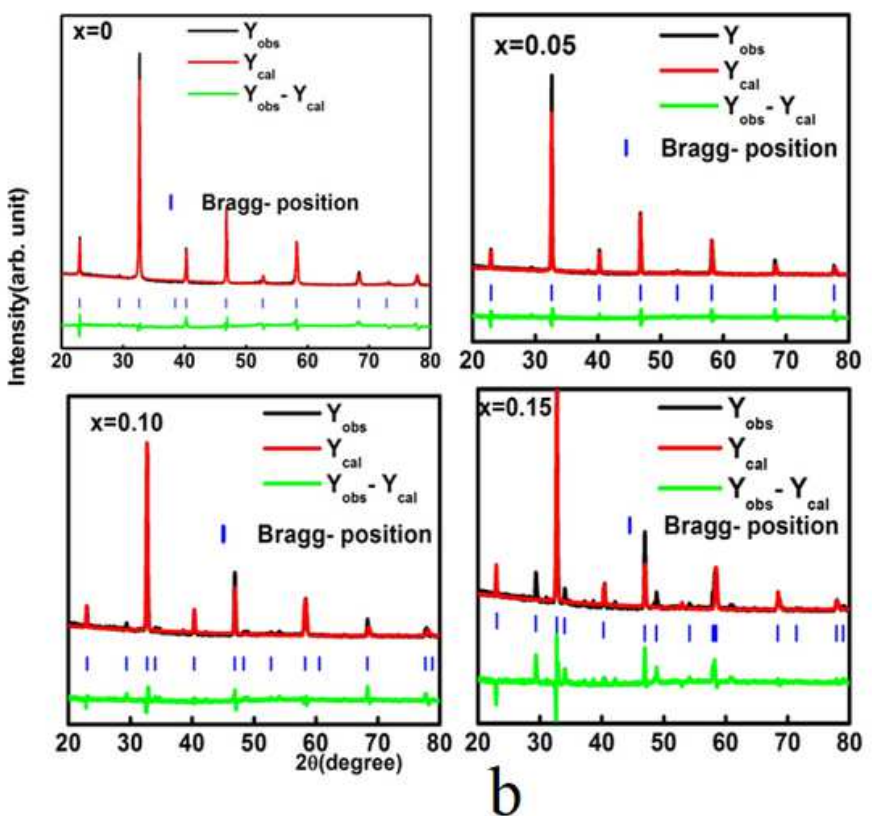

Figure 2

2(a): The X-ray diffraction patterns of (1-2x) BNT- $x$ CSn- $x$ CSe compounds with $(x=0,0.05,0.1,0.15)$. 2(b): Rietveld refinement results of (1-2x) BNT- xCSn - xCSe ceramics with $(x=0,0.05,0.1,0.15)$ at room temperature.

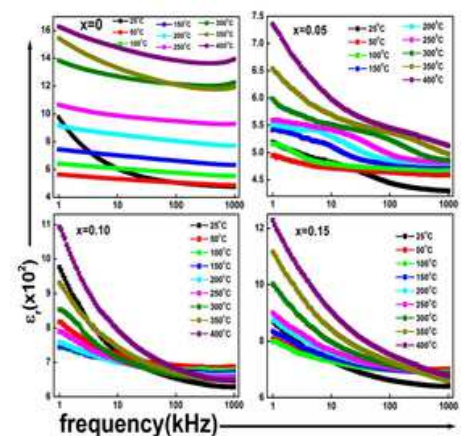

a

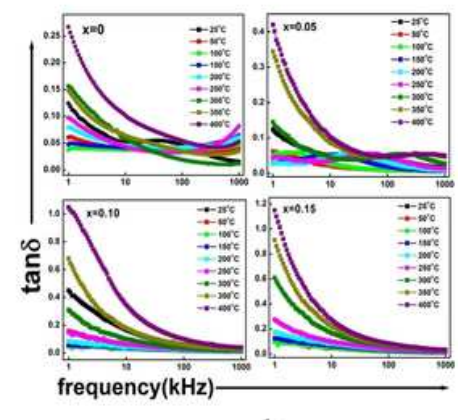

b

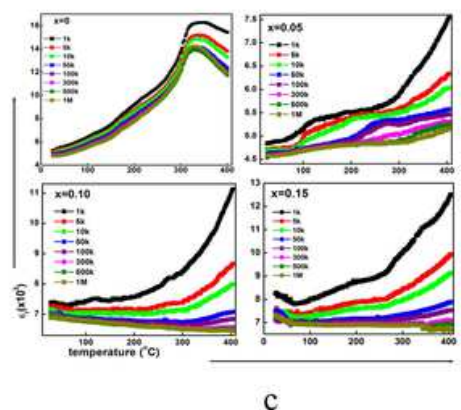

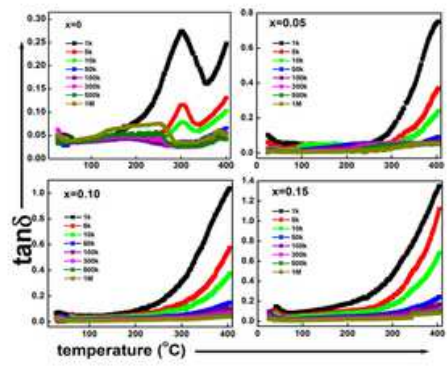

d

\section{Figure 3}

3(a): Frequency dependence of dielectric constant of (1-2x) BNT- x CSn - x CSe compound at different temperatures $(250-400 o C)$ with $(x=0,0.05,0.1,0.15)$. 3(b): Frequency dependence of dielectric loss of (1$2 x)$ BNT- $x$ CSn $-x$ CSe compound at different temperatures $(25 o-400 \circ C)$ with $(x=0,0.05,0.1,0.15) .3(c)$ : Temperature dependence of dielectric constant of (1-2x) BNT- $x$ CSn - $x$ CSe compound at different frequency $(1 \mathrm{kHz}-1 \mathrm{MHz})$ with $(x=0,0.05,0.10,0.15)$. 3(d): Temperature dependence of dielectric loss of (1$2 x)$ BNT- $x$ CSn $-x$ CSe compound at different frequency $(1 \mathrm{kHz}-1 \mathrm{MHz})$ with $(x=0,0.05,0.1,0.15)$. 

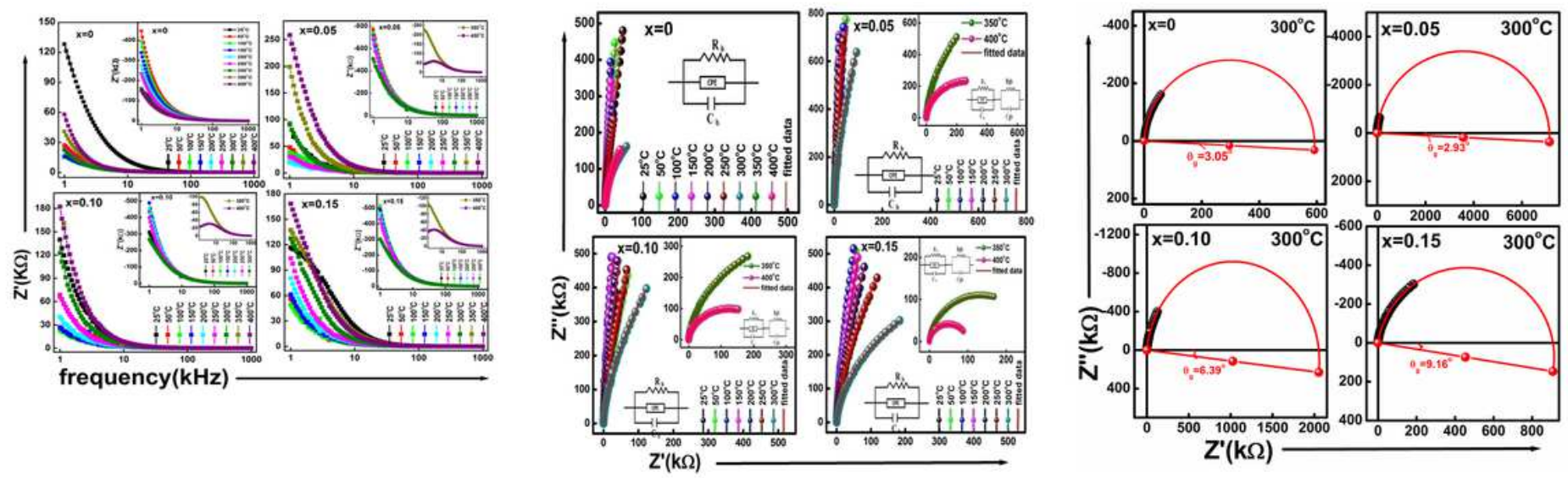

Figure 4

4(a): Frequency dependence of Z' and Z" of (1-2x) BNT- x CSn - x CSe compound at different temperatures $(250-400 \circ C)$ with $(x=0,0.05,0.1,0.15)$. 3.3.1 Frequency dependence of $Z$ ' and $Z " 4(b)$ : Nyquist plot of (1-2x) BNT- $x$ CSn $-x$ CSe at at different temperatures $(250-400 \circ C)$ with $(x=0,0.05,0.1$, 0.15). 4 (c): The semicircle of Nyquist plot of (1-2x) BNT- $x$ CSn $-x$ CSe at $3000 C$ with different concentrations $(x=0,0.05,0.10,0.15)$.
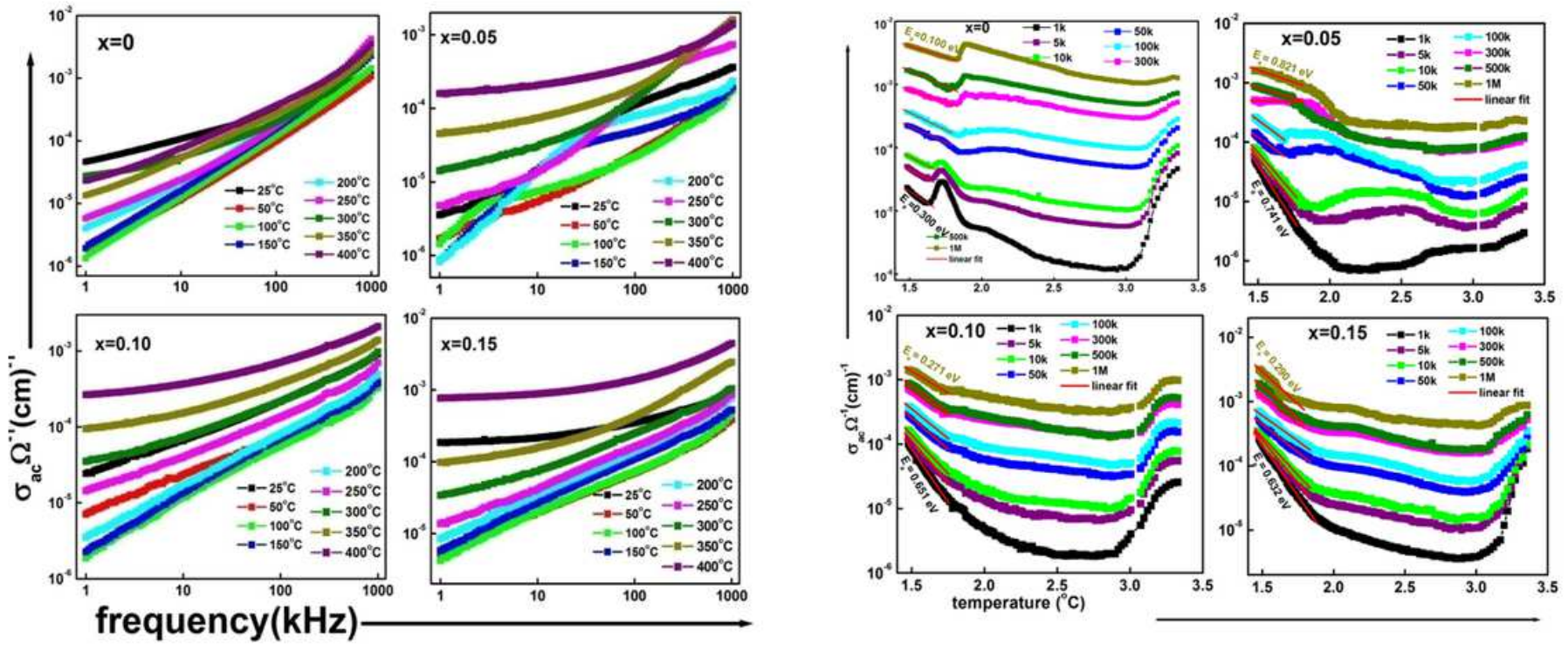

\section{Figure 5}

5(a): Frequency dependence of ac conductivity of (1-2x) BNT- $x$ CSn $-x$ CSe ceramics at different temperatures $(25 \mathrm{o}-400 \mathrm{oC})$ with $(\mathrm{x}=0,0.05,0.1,0.15) .5(\mathrm{~b})$ : Variation of AC-conductivity with inverse temperature of (1-2x) BNT- $x$ CSn $-x$ CSe ceramics at different frequency $(1 \mathrm{kHz}-1 \mathrm{MHz})$ with $(x=0,0.05$, $0.10,0.15$ ). 


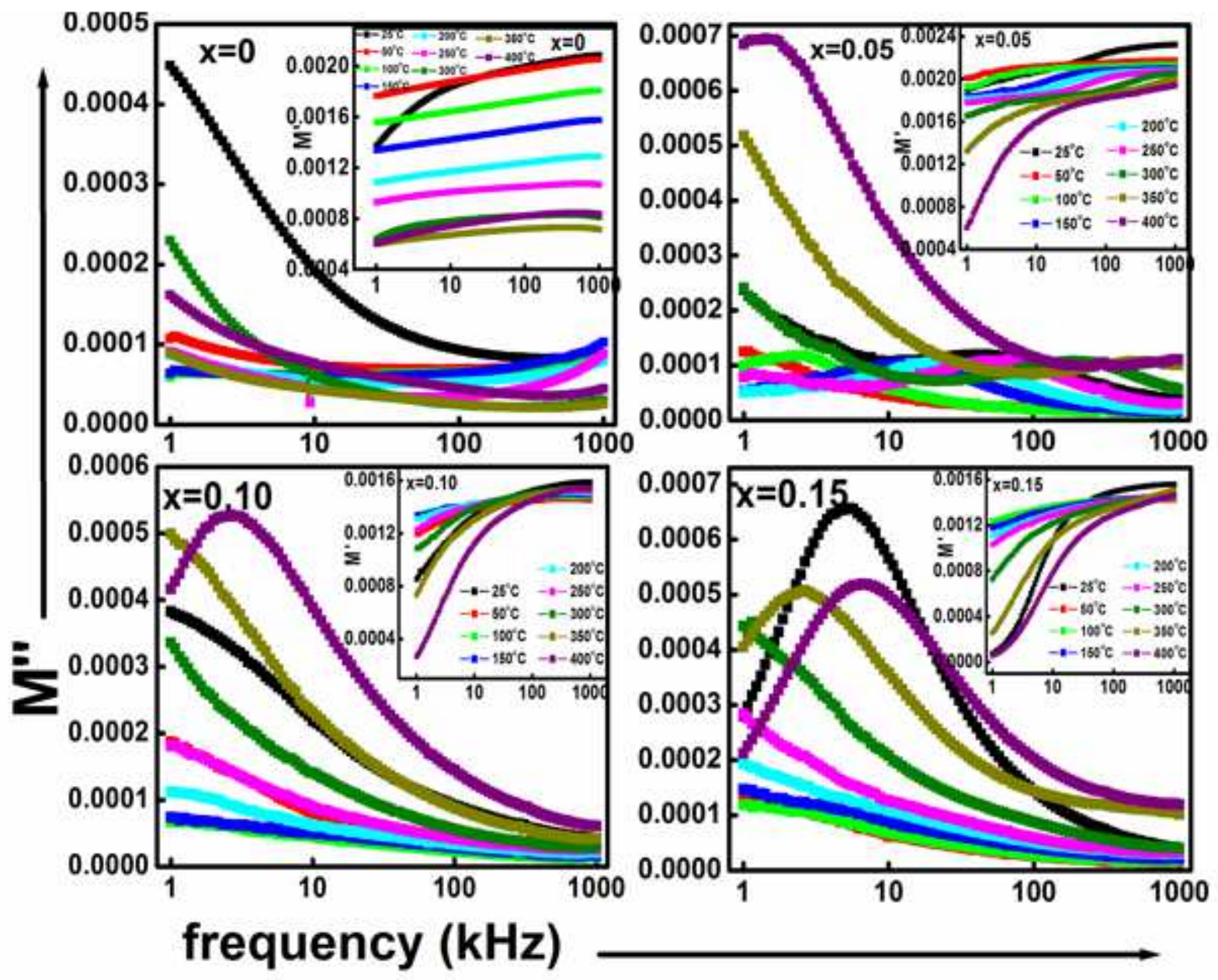

Figure 6

Frequency dependence of $\mathrm{M}^{\prime}$ and $\mathrm{M}$ " (1-2x) BNT- $x$ CSn $-x$ CSe ceramics at different temperature (25oC$400 \mathrm{oC})$ with $(x=0,0.05,0.10,0.15)$. 


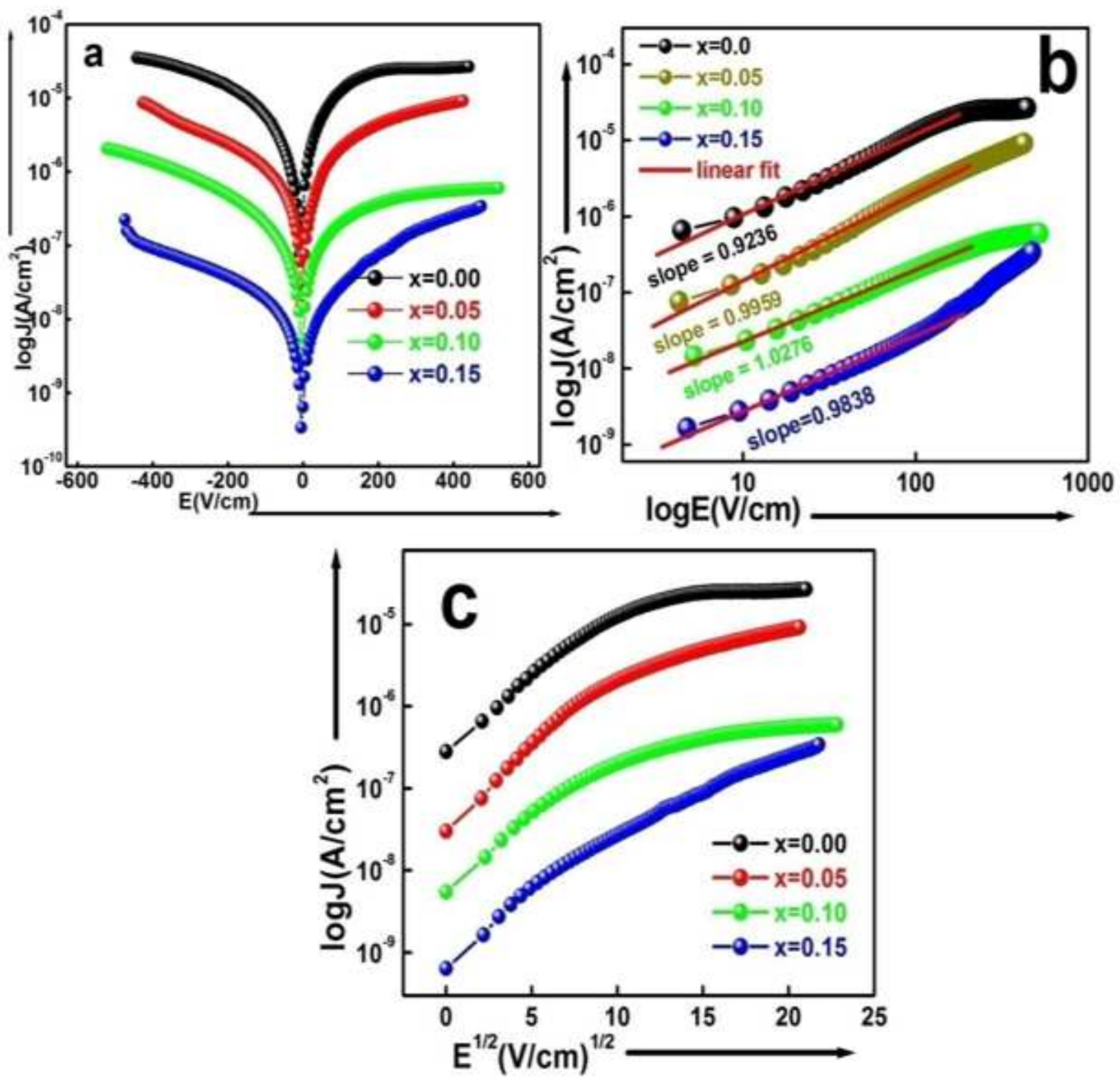

Figure 7

(a) $\log J$ versus E plot (b) log $J$ versus log E plot, (c) log J versus E1/2 plot of (1-2x) BNT-x CSn - x CSe at room temperature for different concentrations $(x=0,0.05,0.1$ and 0.15$)$. 


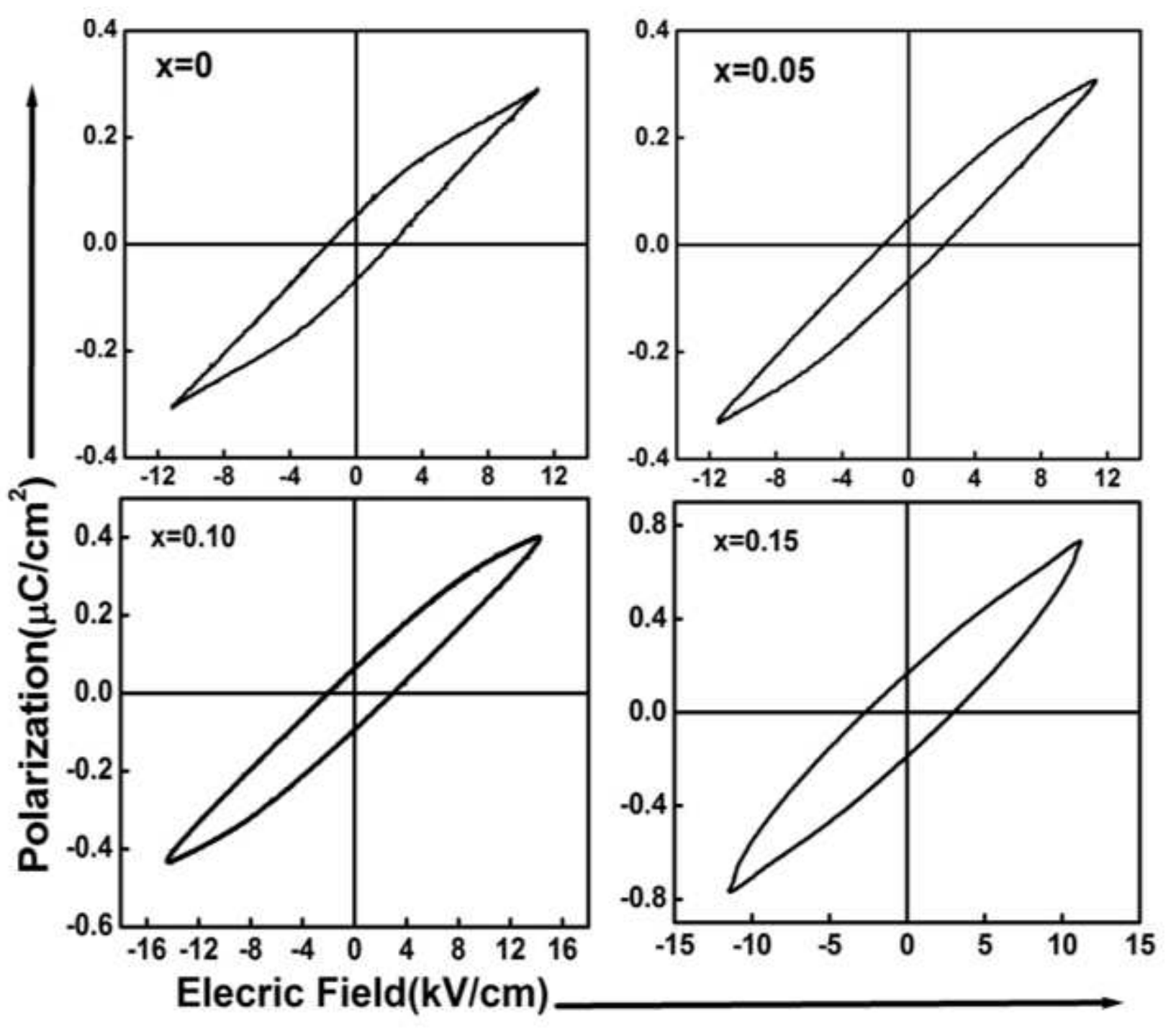

Figure 8

P-E hysteresis loop of (1-2x) BNT-x CSn- $x$ CSe ceramics with different concentration $(x=0,0.05,0.1,0.15)$ at room temperature. 